\title{
Review Article \\ CFG Pile Composite Foundation: Its Engineering Applications and Research Advances
}

\author{
Bantayehu Uba Uge $\mathbb{D}^{1,2}$ and Yuan-Cheng Guo ${ }^{1}$ \\ ${ }^{1}$ School of Civil Engineering, Zhengzhou University, Zhengzhou 450001, China \\ ${ }^{2}$ School of Civil Engineering, Hawassa University, Hawassa, Ethiopia \\ Correspondence should be addressed to Bantayehu Uba Uge; bantayehuu@gs.zzu.edu.cn
}

Received 11 August 2020; Revised 15 September 2020; Accepted 15 October 2020; Published 30 October 2020

Academic Editor: Huining Xiao

Copyright (C) 2020 Bantayehu Uba Uge and Yuan-Cheng Guo. This is an open access article distributed under the Creative Commons Attribution License, which permits unrestricted use, distribution, and reproduction in any medium, provided the original work is properly cited.

\begin{abstract}
Problematic soils exist almost everywhere on the globe. State-of-the-art solutions to make civil engineering infrastructures built on them are still highly sought. The CFG (cement-fly ash-gravel) pile composite foundation system has been widely used in buildings, highways, railways, and bridge transition sections owing to its proven engineering characteristics in soft ground treatment. This paper discusses about the development and achievements of its engineering applications, along with possible future research directions. The remarkable evolution took place in the past to address projects' strict differential and postconstruction settlement control requirements including embedding the geosynthetic layer into the load transfer platform and combining it with rigid slabs, as seen implemented in few CFG pile-supported embankments. It was also observed that the interaction of the existing CFG pile composite foundation with an adjacent new foundation pit excavation inevitably presents a complex soil-structure interaction mechanism among the fundamental components-the retaining wall, mat, piles, cushion, and soil.
\end{abstract}

\section{Introduction}

Consumption of industrial wastes as dust and/or aggregate in geotechnical application is developing globally. Cementfly ash-gravel (CFG) piled composite foundation is a part of it where the by-product fly ash is used as a constituent material to improve poor engineering properties of soft or weak foundation soils using column technology. A CFG pile with higher bond strength is achieved by mixing cement, fly ash, crushed stone, stone chips, and sand with water. An increase in its engineering application has been seen in China in the last decades with the aim to increase the overall bearing capacity of the natural soft ground and reduce possible uneven settlement of the foundation [1-5]. Steel reinforcing bars are not usually needed inside the pile, and the industrial waste-fly ash is used as an admixture for the concrete [6]. The akin column technology commonly used to improve the soft ground in the USA is termed as "rammed aggregate piers." [7] Other internationally practiced vertical substructural elements installed to enhance the engineering behaviour of the soft ground include geosynthetic-encased stone columns [8], mechanically mixing in situ soil with chemical agent-deep mixed columns (DM) $[9,10]$, and using hydraulic means-grouted columns [11]. While reviewing the latest research studies on the CFG pile composite foundation, concepts were also taken from such similar soft ground improvement technology. On the contrary, as the word "composite" is conveniently used hereunder as appeared as agreeably by practitioners and researchers in the area, the reader is advised to avoid conflating the nomenclature with other composites prepared from packaging materials such as biodegradable composites. So, one may look at the works of several researchers viz. listed in [12-15] for composites resulting from organic coatings, natural fibres, and biopolymers.

Remarkable research works have experimentally, analytically, and numerically been carried out to comprehend the mechanism of interaction among the soil, pile, and supported structure in the CFG pile composite foundation system [16-21]. Unlike the traditional pile foundation, piles 
in the CFG pile composite foundation receive structural load in an integrated way that involves the contribution of top soil between piles. The bearing capacity of the soil between piles is sufficiently utilised by providing an appropriate thickness of the mattress layer between the piles' head and the base of the supported structure. Because of the stress concentration on top of piles, piles will puncture upward into the cushion layer (see Figure 1); thus, the load is partly transferred through negative side friction developing on the upper pile part. After the neutral depth, the negative skin friction reverts into positive. The depth of the neutral plane is mostly located above the mid; and for the rigid end-bearing pile composite foundation, it may range from 0.15 to 0.35 times the pile length $[16,22,23]$. In Figure $1, S_{S}$ is the total compression deformation of the soil between piles; $\delta_{p}$ is the total compression deformation of the rigid pile; $S_{1}$ and $S_{2}$ are the settlement difference between the top and the bottom of the soil layer in the reinforcement area after loading, and $S_{3}$ and $S_{4}$ are the settlement of the pile top and the pile bottom, respectively; $\delta_{1}$ and $\delta_{2}$ are the rigid pile head puncture into the cushion layer and its tip settlement in the underlying soil layer, respectively; $l$ and $l_{0}$ are the pile length and the depth of the neutral plane, respectively; and $h_{c}$ is the thickness of the interposed layer.

Many authors studied the effect of cushion thickness and its engineering properties on the load redistribution mechanism [24-27]. Studies indicated that, beyond a certain thickness, the cushion effectiveness appeared to be quite negligible. Similarly, the increase in the cushion thickness beyond the optimum depth level had limited influence on the depth of the neutral surface and pile-soil stress ratio. Thus, for a reasonable and efficient load distribution of pilesoil, an appropriate thickness of the cushion layer shall be provided. Experimental and numerical analyses have indicated that the pile-soil stress ratio increased as the loading increased to a certain level to attain a stable state afterward $[23,28,29]$. One can easily observe from Figure 2 that the pile-soil stress ratio depends on multiple parameters; for example, it decreases as the thickness of the cushion layer increases and gets approximately a constant value at some point $[23,30-32]$.

The pile-soil stress ratio is an important reflection parameter for the working condition of the CFG pile composite foundation. Tradigo et al. [33] discussed the mechanism of cushion layer compression during vertical load transmission. They showed that, as the two stiff bodies (pile and raft) approached the cushion from top and bottom, plastic strains developed and spread from the head of the piles. Based on deformation and shear strain contours in the cushion layer, Rui et al. [34] discussed developing a soil-arching phenomenon with a multitrapdoor test apparatus and verified the similarity of the slip surface and deformation pattern with that of the diffusion cone model. They disclosed that the cushion's load redistribution capability depended on the interposed layer thickness and its properties, as well as pile spacing. Boussetta et al. [35] investigated the cushion thickness effect on the pile-soil stress ratio for a rigid and flexible foundation system. Their study indicated that, up to a certain thickness of the mattress layer, the efficiency of rigid inclusion in receiving the applied load increased for the rigid foundation compared to embankments (flexible foundation). Similar inference has been forwarded with numerical analyses [36]. As piles are practically used in a group, the group effect affected the pile-soil stress ratio $[37,38]$. The pile spacing, as it was somehow related to the area replacement ratio, to be discussed later, influenced the load shared by the piles.

In order to save investment cost, some practitioners combined various foundation treatment methods to form a mixed pile composite foundation consisting of different pile types and/or different lengths of piles. The engineering practice of such a new composite foundation exploits the contribution of the shallow soil strengthened by more flexible or short piles together with the mobilized bearing capacity of long piles in the deeper strata [17,39-43]. To mention some, Liu et al. [40] and Zhang et al. [44] discussed about piles of different flexibilities. Ge et al. [45] and Lu et al. [46] reported about employing different lengths. Hou [47] investigated the vertical force transmission mechanism of a rigid long-short pile composite foundation. Regarding dissimilar material types, Zheng et al. [48] conveyed about CFG-lime usage, and Zhang et al. [4] gave attention to CFG piles used in all parts but rigid concrete piles under the slab edge. Zhang and Zhang [49] experimentally studied CFG piles combined with vibroreplacement stone columns. All these multipile composite foundations emerged to fulfill the need for modifying the rigidity and stability of the poor subsoil as well as drainage requirements to accelerate excess pore water pressure dissipation. On top of that, it is noteworthy that none is omnipotent by itself but has a certain application scope as far as any soft ground treatment method is concerned.

\section{Bearing Capacity and Settlement Characteristics}

Like any other foundation system, CFG pile composite foundation has to be checked for both its capacity to bear superstructural load and its settlement characteristics as the load being transmitted through time. So far, as the literature shows, the bearing capacity can reasonably be estimated by using the following equation [50-53]:

$$
f_{\mathrm{spk}}=m_{1} \frac{R_{a 1}}{A_{p 1}}+\beta_{1} m_{2} \frac{R_{a 2}}{A_{p 2}}+\beta_{2}\left(1-m_{1}-m_{2}\right) f_{\mathrm{sk}},
$$

where $m_{1}, m_{2}$ are the replacement rate of the long pile and short pile, respectively; $\beta_{1}, \beta_{2}$ are the strength reduction coefficient of the short pile and soil between piles, respectively; $R_{a 1}, R_{a 2}$ are the characteristic values of the vertical bearing capacity of the long pile and short pile, respectively (see equation (2)), which can be determined according to the static load test or the bearing capacity of a single pile determined by the strength of the pile body; $A_{p 1}, A_{p 2}$ are the cross-sectional area of the long pile and short pile, respectively; and $f_{\text {spk }}$ and $f_{\text {sk }}$ are the characteristic values of the bearing capacity of the composite foundation and soil between piles, respectively. 


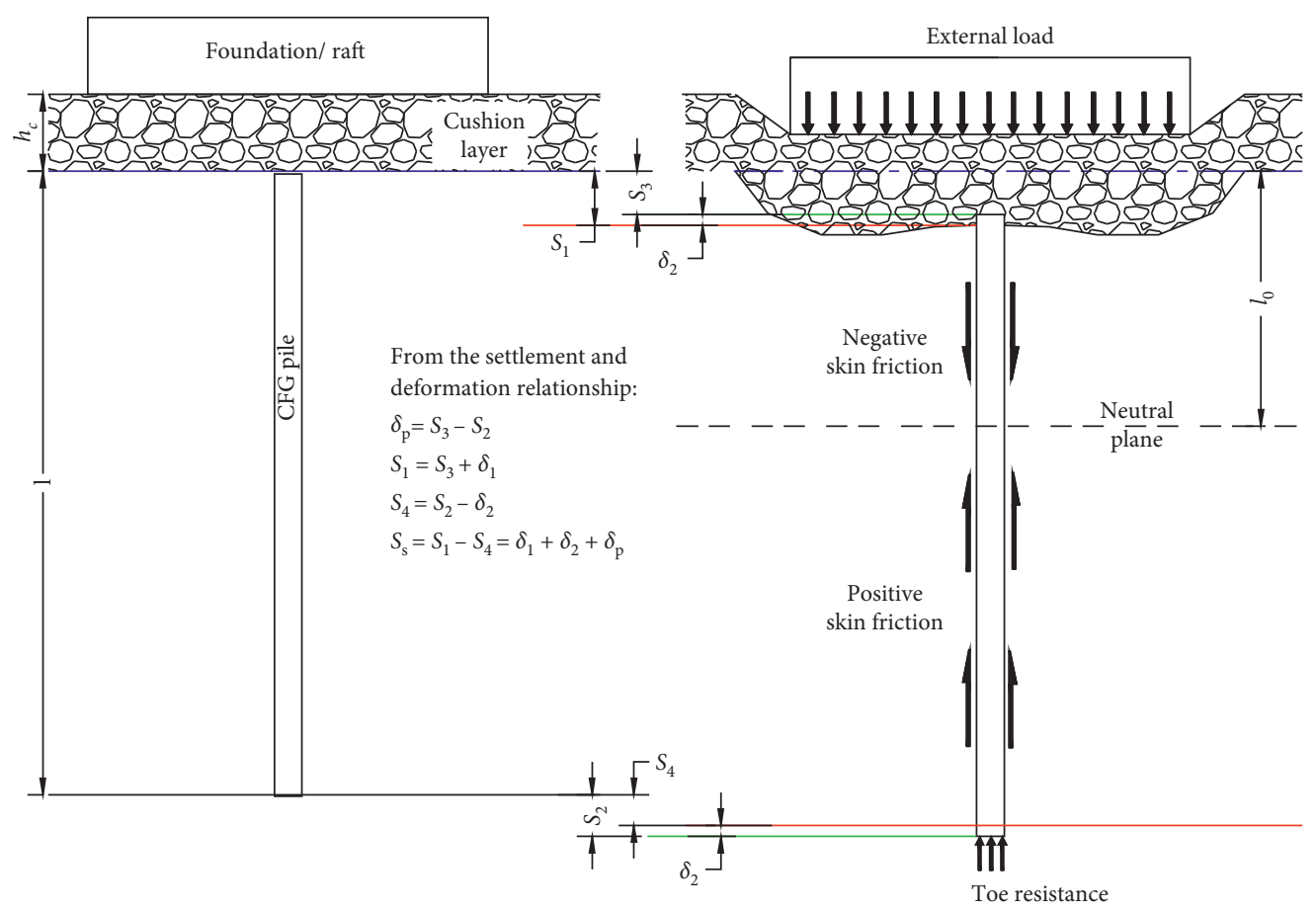

Figure 1: Load transfer mechanism and simplified deformation calculation (modified after [22, 23]).

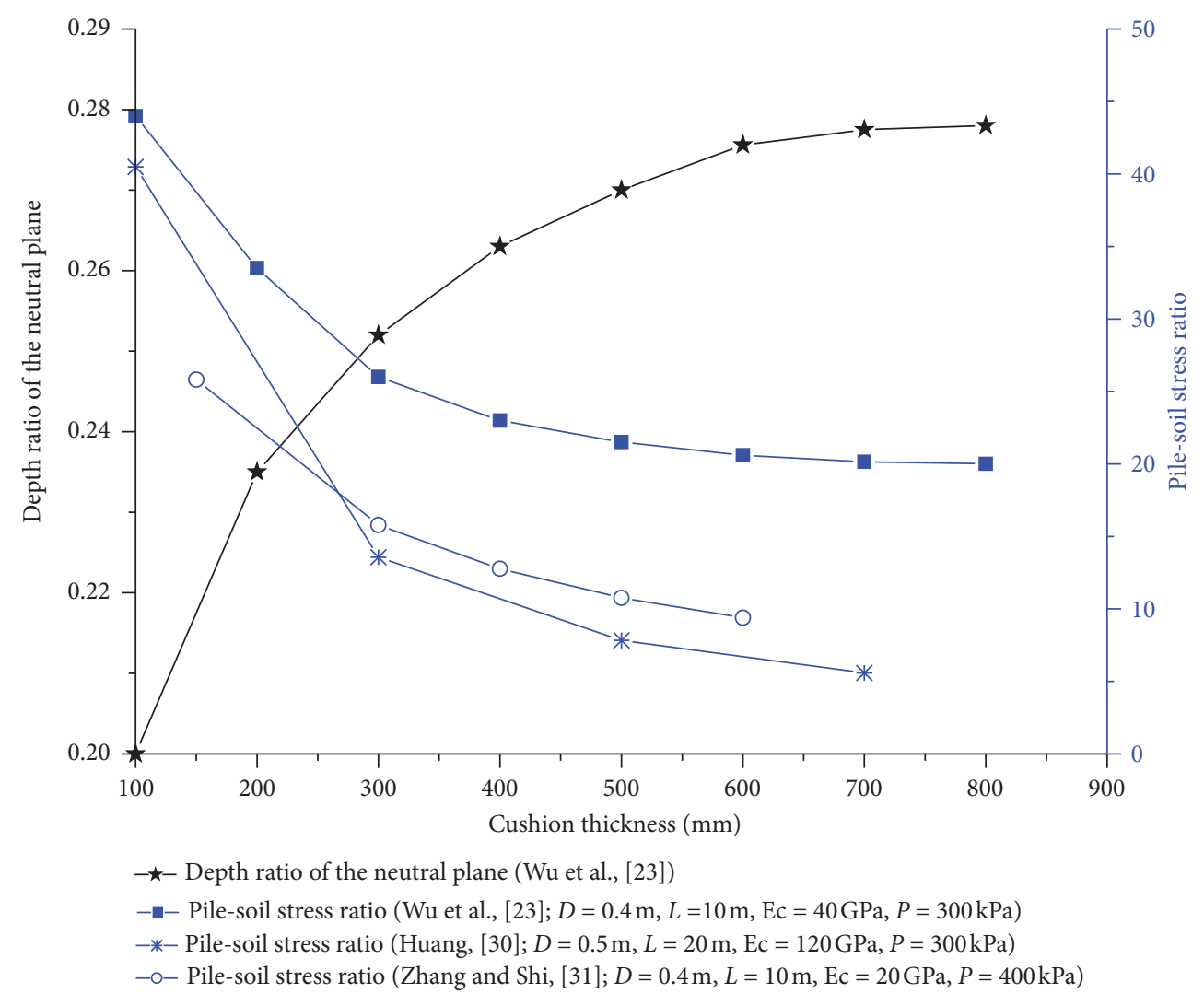

Figure 2: Cushion thickness vs. depth ratio of the neutral plane and pile-soil stress ratio [23, 30, 31]. 
The characteristic values of the vertical single-pile bearing capacity can be calculated from

$$
R_{a_{1 / 2}}=u_{p_{i}} \sum_{i} q_{s i} l_{i}+A_{p} q_{p}
$$

where $u_{p_{i}}$ is the perimeter of the pile in the $i^{\text {th }}$ soil layer, $q_{s i}$ is the eigenvalue of the pile skin resistance of the $i^{\text {th }}$ soil layer, $q_{p}$ is the eigenvalue of the pile toe resistance, and $l_{i}$ is the $i^{\text {th }}$ layer soil thickness.

According to Yuan et al. [53], there existed a difference in the value calculated for $R_{a}$ according to specifications and that obtained from the single pile test. Reasoning it to happen because of an increase in the side resistance during testing, they proposed the enhancement factor to account for the discrepancy. Noticing equation (1), the bearing effect would also be affected by the area replacement ratio, i.e., the coverage rate reflecting CFG piles' area proportion, which in turn is affected by the pile diameter and spacing. Increasing pile spacing results in a lesser load-sharing ratio between the pile and the soil [37]. On the contrary, provision of caps at piles' head increases the replacement ratio and pile-soil stress ratio [37, 54]. Boussetta et al. [35] disclosed that an increase in the replacement ratio by increasing the pile head diameter improved the efficiency, meanwhile, resulting in a settlement reduction up to $50 \%$. The centrifuge investigation conducted by Li et al. [55] also pointed out reduction in the pile-soil stress ratio as the replacement rate was increased. It can, thus, be said that the pile-soil load-sharing ratio is an important performance indicator as far as the working mechanism of the CFG pile composite foundation is concerned $[28,56]$. The strength reduction coefficient between pile $\beta$ shows the interaction mechanism between the pile and its surrounding soil. As piles are being loaded, the shear strain increases in the vicinity of loaded piles, which leads to soil stiffness nonlinearity and anisotropy. Likewise, the natural uneven distribution of the soil layer makes obtaining a single value of $\beta$ to be unachievable, but approximate estimation. Moreover, for the multipile composite foundation, the exact value of $\beta$ that would simultaneously make full mobilisation of the geotechnical bearing capacity for both short and long piles is currently unattainable. In fact, as far as pile-soil-pile interaction behaviour of the group is concerned, consideration for interactive pile-soil displacements remains to be the hottest topic [47, 57-62].

The settlement of the composite foundation comprises the settlement of both the reinforcement zone and the underlying soil layer. According to the Chinese code for design of building foundation, GB 50007-2011, the settlement calculation can be made using the following equation:

$$
\begin{aligned}
S= & \psi_{s p}\left[\sum_{i=1}^{n_{1}} \frac{P_{0}}{\xi E_{s i}}\left(z_{i} \overline{\alpha_{i}}-z_{i-1} \bar{\alpha}_{i-1}\right)\right. \\
& \left.+\sum_{i=n_{1}+1}^{n_{2}} \frac{P_{0}}{E_{s i}}\left(z_{i} \overline{\alpha_{i}}-z_{i-1} \bar{\alpha}_{i-1}\right)\right],
\end{aligned}
$$

where $\psi_{s p}$ is the empirical settlement calculation coefficient, ranging between 0.2 and $1.0 ; n_{1}$ and $n_{2}$ are the number of soil layers in the strengthened area and the rest in the settlement calculation depth, respectively; $P_{0}$ is the additional pressure at the bottom of the basement $(\mathrm{kPa}) ; \xi$ is the increasing coefficient of compression modulus of the composite soil layer obtained by dividing the characteristic values of the bearing capacity of the composite foundation to those of the natural foundation; $E_{s i}$ is the compression modulus of the $i^{\text {th }}$ soil layer $(\mathrm{MPa}) ; z_{i}$ and $z_{i-1}$ are the depth between the basement bottom and that of the $i^{\text {th }}$ soil layer and the $(i-1)^{\text {th }}$ soil layer (m), respectively; and $\overline{\alpha_{i}}$ and $\bar{\alpha}_{i-1}$ are the average additional stress coefficients between the point of calculation on the basement bottom and the bottom surface of the $i^{\text {th }}$ soil layer and the $(i-1)^{\text {th }}$ soil layer, respectively.

Equation (3) was developed based on isotropic homogeneous linear deformation theory. It is unable to capture the effect of large loads on the stress-strain behaviour of the adjacent soil in $3 \mathrm{D}[2,63]$. Hence, a more rigorous theoretical approach which reflects the soil nonlinear and stress path-dependent characteristics needs to be developed.

Another interesting issue that drawn both practitioners and researchers was postconstruction settlement. It has recently received growing attention owning to the move in design focus from bearing capacity to performance requirement, particularly regarding uneven settlement $[64,65]$. The difference in the settlement value between the final and that at the moment of commencing intended use of infrastructures defines the postconstruction settlement, which can be expressed as

$$
S_{\mathrm{gh}}=S-S_{e}-S_{t},
$$

where $S_{\text {gh }}, S, S_{e}$, and $S_{t}$ are the postconstruction settlement, cumulative (final) settlement, immediate settlement, and consolidation settlement just at the instant the infrastructure begins its service, respectively.

The common methods used to determine the final settlement include the three-point, Asaoka, and the hyperbolic methods $[66,67]$. It would become of great importance to develop procedures that will seize observed settlement data in earlier construction stages to predict postconstruction settlements and/or subsequent construction stages. Zhang et al. [66] used both the residual primary consolidation settlement (from the three-point method and/or Asaoka method) and the secondary consolidation settlement (using the coefficient of secondary consolidation) to calculate the postconstruction settlement on a typical soft soil foundation. Junjun and Xinghua [65] used the gray system theory for predicting the postconstruction settlement by improving the basic model to accommodate for unequal observation time interval for settlement observation data from the bridge group pile settlement. On the contrary, Niu et al. [63] applied 3D numerical analysis to estimate the total and differential settlement of the basement raft by crosschecking the result with theoretical calculations according to equation (3).

Scholars have also used the shear stress distribution and its range of influence around the pile to predict the composite foundation settlement $[68,69]$. As piles are practically used in a group, based on how close the piles are to each 
other, there will be a group interaction effect producing an overlap of stress and displacement field, i.e., the sheltering and reinforcing effect of piles in the group [47, 70-72]. In order to reduce the complexity associated with the variation of pile-soil interaction along the pile length, the skin friction distribution, the stiffness difference among the constituting elements such as the cushion, the raft foundation, the CFG pile, and the soil, etc., the unit cell reinforcement analysis under equal stress or equal-strain ideal boundary condition has often been chosen by researchers [73, 74]. The unit cell (as shown in Figure 3(a)) isolated from the group contains a single CFG pile surrounded by the soil and acts as a column which may or may not be allowed to deform laterally. When lateral deformation of the unit cell is considered during analysis, it results in a lower stress concentration ratio than that analysed without allowance for lateral deformation $[7,73]$. However, still many researchers prefer to use numerical analysis for the settlement investigation of reinforced soft ground $[63,75,76]$.

\section{Engineering Applications}

3.1. Embankments Constructed over Soft Ground. CFG pile composite foundation has increasingly been implemented in weak soil deposits as column technology either alone [77, 78] or combined with (i) geosynthetic reinforcement $[19,59,67,79,80]$, (ii) concrete slabs $[4,81]$, and (iii) other technologies such as prefabricated vertical drains $[49,82]$. It has been widely employed both in new project routes and widening existing embankments. When an existing pavement is widened because of growing traffic demand, CFG piles can be used to support the new added embankment to eliminate pavement distresses due to the differential settlement at the overlapping area [83]. From experience, the stability and performance of the high embankment can be well improved by embedding the geosynthetic layer into the load transfer platform $[84,85]$. When the CFG piles are used in conjunction with geosynthetic grids connected to the pile's head, the load transfer mechanism involves soil arching above the pile caps, and the geosynthetic membrane becomes under tension (see Figure 4) [88-91]. The soil arching induces shear stresses that are resisted by the tension membrane effect of the single geogrid layer or the stiffened platform of the multilayer geosynthetic system. As a matter of fact, soil-arching effect and its practical advantages have been well recognized among the geotechnical engineering society; since from the time Terzaghi illustrated it with a yielding "trapdoor," it has become more popular when dealing with piles and other geostructures surrounded by either vertically or laterally moving soil mass [92-99].

The stress concentration ratio (the ratio of column stress to the stress borne by the soil) of piled supported embankments without the geosynthetic membrane was reported to be lesser than that with geosynthetic reinforcement $[100,101]$. However, as reported by some scholars, the performance of the conventional geosynthetic-reinforced and piled-supported (GRPS) embankments constructed over poor soil deposits has still been shown to have intolerable uneven settlement, relatively larger horizontal displacement, and other instability problems, especially in the face of the stringent high-speed railways' requirement $[80,102,103]$. Under such circumstances, it is prudent to go for a relatively rigid slab to eliminate possible differential settlement. Provision of the slab in the CFG pile-slab structure (CFGPSS) also addresses the highest concern for the postconstruction settlement in high-speed railway (HSR) embankments, which should be limited under the maximum allowable settlement recommended by standard codes (e.g., Chinese Standard TB10001-2016 and British Standard BS8006-1-2010).

Jiang et al. [81] presented numerical analysis for the Beijing-Tianjin HSR embankment constructed using the CFGPSS. They measured and closely monitored the transverse differential settlement profiles of the slab to examine the efficiency to meet the stringent postconstruction requirements. According to their field measurements, a maximum of about $3 \mathrm{~mm}$ differential settlement between the centreline and the toe of the embankment was found throughout the construction period. Zhang et al. $[4,104]$ also conducted study on the Beijing-Shanghai HSR to examine the effectiveness of the CFGPSS and found a remarkable settlement-controlling effect.

Another potential application area is treating soft foundation soils for embankments constructed in the mountainous area. When soft soils appear in the mountain area, pavement designers often encounter different engineering characteristics than those of ordinary plain soft foundations. CFG pile composite foundation is one of the main methods of soft foundation treatment under such condition [78].

CFG piles have also been applied to tackle engineering problems related with the bump at bridge approaches. This was one of the common challenges attracting researchers to investigate abutment piles subjected to lateral soil movements [105-109]. A bridge would be unable to offer its intended service if its approach is prone to discontinuities resulting from differential settlement of the approach embankment. Xiao et al. $[110,111]$ used centrifuge model tests and 3D numerical analysis with the finite difference code FLAC3D to examine the performance of the CFG-piled bridge approach embankment with geosynthetic. Their result indicated the shielding effect of CFG piles on the lateral soil displacement, and the settlement of the improved embankment was substantially reduced as the CFG pile transferred the load to the deeper soil depth. Hence, the performance of abutment piles was evidently improved. However, beyond the threshold ground replacement ratio $(\mathrm{m})$ of $4.8 \%$, the efficiency of CFG piles was seen to be limited. Li and Bian [112] numerically showed using ABAQUS that the dynamic behaviour of the transition zone at the bridge and the approach embankment section was improved because of implementing CFG piles of varying length. It was also shown that the amplified dynamic response, resulting from rail irregularity (track geometry degradations) due to sudden stiffness variations as the train moves with high speed, was effectively smoothened by employing CFG 


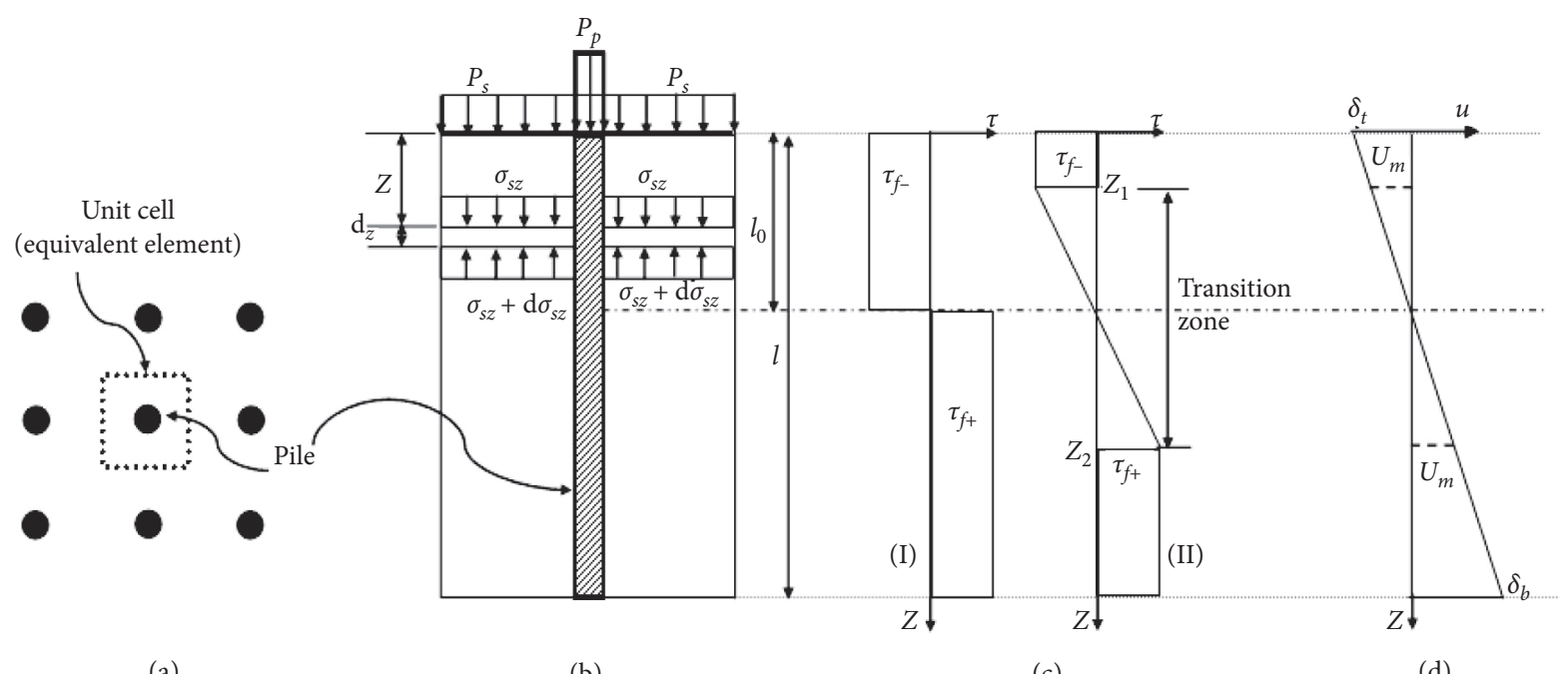

(a)

(b)

(c)

(d)

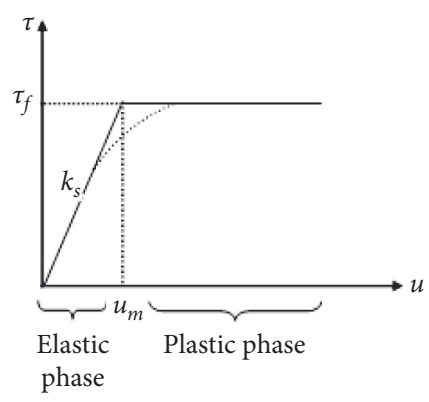

(e)

FIgURE 3: Simplified distribution of the pile shaft resistance and relative pile-soil displacement. (a) Plane view. (b) Elevation view. (c) Simplified shaft friction distribution. (d) Simplified pile-soil relative displacement. (e) Elastic-plastic mechanical property.

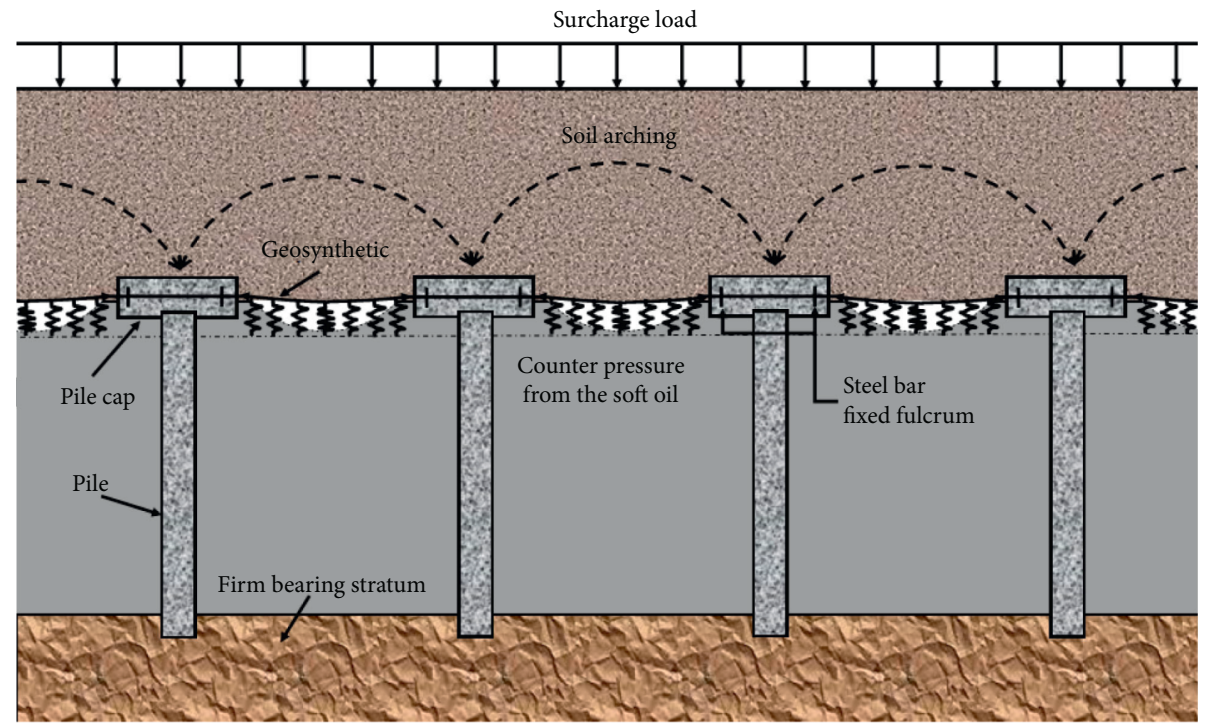

FIgURE 4: Typical load transfer mechanism in the fixed geosynthetic-reinforced and pile-supported embankment [86, 87].

piles, and the piles neighbouring the bridge had borne higher dynamic loading when the train passed the transition zone. It was also noted that the cushion layer offered good seismic performance by reducing the dynamic shear wave transmission along with the base isolation system [113, 114]. Interested reader about the dynamic 
characteristics of the CFG-piled composite foundation can also refer to $[41,115-118]$.

3.2. Support for Superstructures. The literature on superstructures overlying on the CFG pile composite foundation is extensive [42, 45, 50, 63, 119-122]. Shen et al. [2] stated that its engineering application in China has begun as a supporting technology for multistorey buildings on the soft ground and further expanded to a wider range of applications. For instance, GRPS platforms have also been applied to control total and uneven settlement for storage tanks $[101,123]$. In fact, on a global scale, different naming is given to the foundation system somewhat similar to the CFG pile composite foundation. It comprises "rigid inclusions" $[35,36,124]$, "cushioned piled rafts" or "pile-enhanced rafts" [27, 125], "unconnected piled rafts" [126], "disconnected piled rafts" [127, 128], "noncontacted piled rafts" [22, 129], "rafts on settlement reducing piles" [130-132], and "nonconnect piled rafts" [133-135]. These studies have been conducted numerically and experimentally to describe the load-sharing mechanism of this novel foundation system. The load transmission by provision of a gap filled with a cushion between the raft bottom and the piles' head was discussed in detail. They all acclaimed the contribution of the interposed layer in diffusing the applied stress to the piles and the surrounding soil. The field static test conducted by Yang and Liu [136] also confirmed the cushion's capability in redistributing the load received from the foundation plate and minimizing the settlement difference between the centre and side areas. Saeedi Azizkandi et al. [135], in their numerical study about the load-sharing mechanism of piles in nonconnected piles, found that the stiffness of the cushion played a great role in transferring a higher portion of the foundation load to pile heads without significant increase in the maximum stress developing in the piles.

The application of the CFG pile composite foundation in liquefying soil has shown a reasonable reinforcement effect against liquefaction [5, 117]. It has also been successfully used in reconstruction projects after an earthquake incident [1]. In situations where superstructural inertial force is large in high seismic regions, disconnecting piles from the raft has been found to help in reducing the stress concentration at the pile head $[22,125,137]$. The resistance to lateral forces resulting from this and other similar horizontal forcegenerating events is usually obtained by mobilizing contact friction along the raft/cushion interface $[5,114,138]$. Studies have shown that the lateral forces and bending moments of piles in nonconnected pile rafts are much smaller than those of the connected pile [139]. It may also be possible to propose geosynthetics to enhance dynamic properties and modify the resistance to shear strain caused by lateral deformation [140].

\section{Discussion}

As is commonly noticed in today's culture, both engineering attributes and economic issues are crucial when choosing appropriate engineering solution. Consequently, some may question how economical the CFG pile composite foundation is. The following brief discussion involves the same and other related engineering perspectives.

4.1. Economic Appraisal. Basically, economic factors depend on the construction material and technology deployed at a particular time-as of a device, technique, or scientific field achieved. Moreover, in the context of green environment ideology, environmentally benign geotechnical construction project is often associated with resource efficiency and land use pattern changes [141]. Increasing attention is being paid to environmental issues to ensure proper management, storage, and/or safe disposal of the huge annual production of fly ash from power plant combustion and municipal waste incarnation, demanding potential application areas for consumption, such as in transportation geotechnics $[141,142]$. The ability to use such residues as a constituent construction material has attracted great attention in the geotechnical community [143-145]. The fly ash in the CFG pile composite foundation is used as an additive and partial cement replacement mixture during concreting. In addition to the environmental benefits of using the industrial byproduct, this "carbon-efficient" cementation material will also affect the plasticity of concrete. It influences the concrete workability, bleeding, water demand, and heat of hydration. It has also been used as aggregate substituting gravel [146].

At present, owing to the maturity of experience and technology, the project cost and construction period for the CFG pile composite foundation have been greatly reduced [1, 147]. It has also been said that CFG is a sustainable emerging construction material [63]. Whether it is implemented in embankment construction or as a disconnected piled raft in building the foundation system, the load has to be transmitted to the natural ground that is made competent by the reinforcing effect of the CFG piles; thereby, both the soil and piles combine to dissipate the load redistributed through the cushion. Suffice to say that the CFG pile composite foundation allows the marginal weak underlying soil to participate in transmitting the applied load, in turn contributing to lower project cost [5]. When the geomembrane is used as described in preceding sections, employing it embraces at least three research areas related to geosustainability issues viz. (1) waste material usage, (2) sustainable ground improvement, and (3) efficient geosynthetics usage. Furthermore, the construction process flow is simple, as depicted in Figure 5. Once the site setting out is done and the CFG concrete mix is ready, hole drilling operation continues to the desired pile depth, and then concreting proceeds. After concrete pouring is finished to a level above the deign elevation, the pile machine mobilizes for the next piling operation. By adjusting the amount and proportion of cement, an optimized CFG pile of strength level between C5 and C25 can be achieved.

4.2. Load Transfer Mechanism. As discussed elsewhere, the load redistribution layer not only ensures the pile and soil 


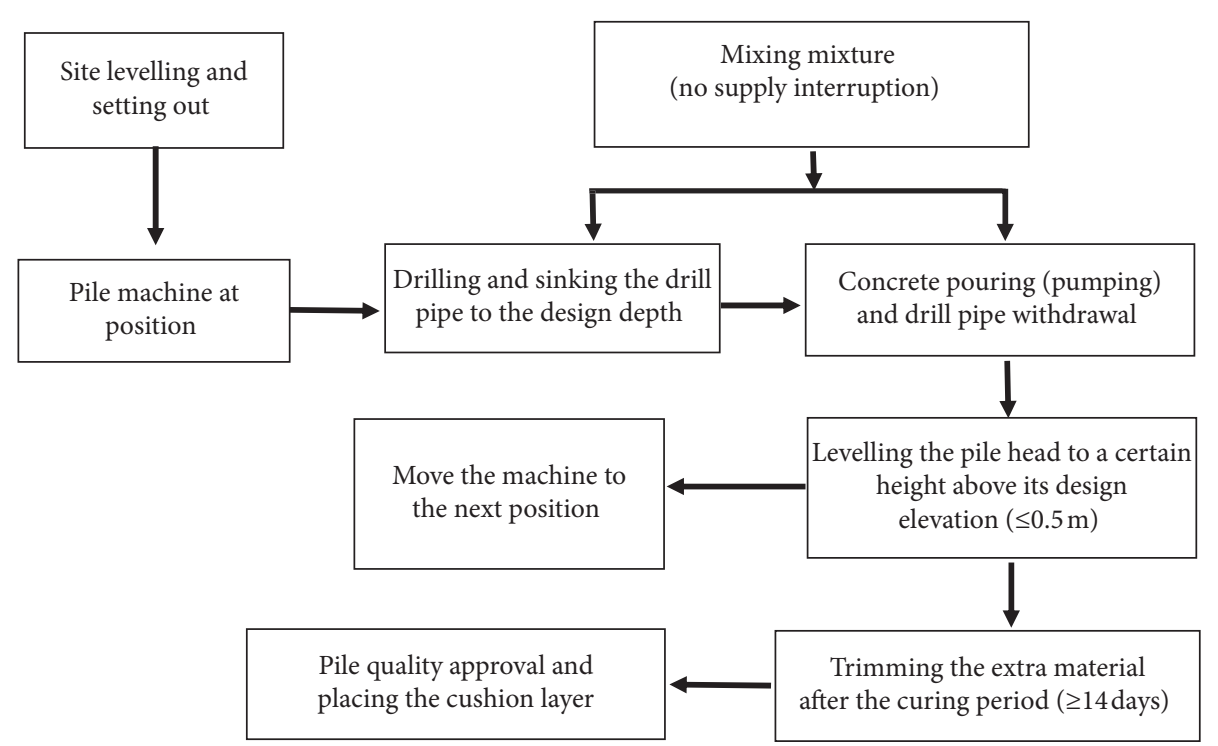

Figure 5: Construction process flow (modified after [148, 149]).

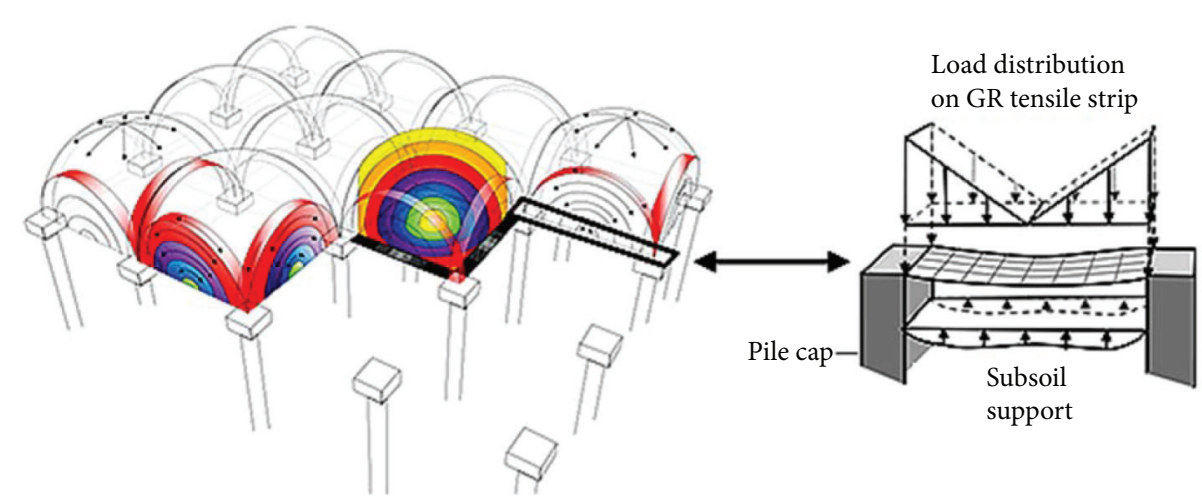

Figure 6: Arching in the geosynthetic-reinforced (GR) pile-supported embankment [159].

bear the load together but also reduces the stress concentration at the bottom of the foundation. In order to effectively play its role, the cushion's frictional characteristic and layer thickness matter a lot. As the frictional characteristic increases, so does the load portion shared by the piles [35]. This is coherent with the reduction of the wage angle as the angle of internal friction increases in Prandtl's failure mechanism, which is usually assumed for the stress distribution limit at the pile head [150-152]. If the pile compresses the cushion layer and continuously penetrates vertically into the cushion layer as the load increases without forming a continuous sliding area in the cushion layer, then the punching shear of the cushion layer occurs [153]. Regardless of the cushion material property, however, an increase in the applied load will increase the vertical stress received by the pile to a certain level, beyond which it will remain more or less constant. In the initial loading stage, the load bearing capacity of the soil is mobilized first, and then the contribution of the pile gradually becomes obvious.

Parametric studies conducted by changing the thickness of the mattress layer indicated that increasing its layer will reduce the load sharing ratio of the piles. The reflection on this can start from the condition that the thickness of the cushion layer is zero. When structural connection is not allowed under the zero-thickness condition, piles will share more load, while the soil takes very small. In other words, when the cushion thickness is small, the pile-soil stress ratio is relatively large, and the bearing capacity of the soil between piles cannot be fully developed. That is, due to the stress concentration of the composite foundation, the stress at the top of the pile is greater, and the stress on the soil between the piles is smaller. If the thickness is increased, an adjustment occurs in such an interaction to increase the load shared by the soil. Nonetheless, beyond a certain value, no benefit would be gained by increasing the thickness. At this point, increasing the thickness of the cushion reduces the load borne by rigid piles while increasing the load taken by the soil between piles, which leads to greater plastic deformation and damage of the soil between piles.

Along with the pressure redistribution as piles pierce into the cushion, soil-arching effect appears due to the modulus difference between the pile and the soil. It results in 
differential movement to draw more load towards the stiffer one. The displacement contours and associated shear strains between adjacent piles form a slip surface patterning either a triangular or an "arch" region depending on the relative cushion thickness and net pile spacing [34, 154]. Similar inference reported by Zhu and Gong [155] shows that based on the cushion thickness and pile spacing, the arching mechanism progressively develops in the cushion layer while redistributing the applied load. This phenomenon of soil arching has particularly good achievement prospect in both conventional and geosynthetic-reinforced CFG-piled embankments and remains to be a hot research perspective for further study [156-158]. Nevertheless, the current state of practice based on numerous analytical, numerical, and experimental (both field and laboratory) investigations confirmed the assumption of the concentric arches model to be valid for a square grid pile arrangement (see Figure 6) $[158,160]$. In the conventional CFG-piled embankments, the deflection of the soil between piles assumes an approximately uniform pattern, while the geogrid reinforcement (GR) strips between the piles deflect less than somewhere else and receive higher load relative to elsewhere.

As the arch development follows the proposed concentric 3D hemisphere illustrated in Figure 6, the connection made between the pile and the GR makes the behaviour of GR pieces along the strip relatively stiffer than those in the middle. The analysis model usually assumes that the arching mechanism transmits the entire load in two steps and decomposes the load into three vertical components. The first step deals with the three components of load transferred because of the arching effect: the portion called " $\mathrm{A}$ " received by the pile ("arching"), "C" taken by the subsoil, and " $B$ " the remainder carried through the geogrids to piles. All are vertical loads. The latter two parts are sometimes collectively termed as the "rest." The second step is carried out to understand the load-deflection behaviour that implicitly divides components $B$ and $C$. In this step, while dealing with membrane action of geotextiles, the residual load transferred by the "rest" is commonly assumed to be distributed either triangularly (e.g., the German design standard-EBGEO, 2010) or in an equal distribution pattern (e.g., British Standard BS8006). However, experimental studies suggested an inverse triangular distribution with the apex around the pile, as depicted in Figure $6[161,162]$. As the pile spacing decreased, the vertical stress distribution was found to be relatively uniform between the end and middle of the span [161]. Another observation deviating from BS8006 was that, for both floating and end-bearing piles, the tensile force in geomembranes continued to increase irrespective of the arching height [163]. Moreover, compared to the unreinforced case, the stress concentration ratio was higher for the geosynthetic-reinforced case due to the membrane effect $[90,101]$. If floating piles are used instead of end-bearing, the stress concentration effect becomes much higher than the effect of both tension membrane and soil arching [164].

In engineering practice, piles are arranged in a square layout $[2,19,68,80]$ or triangular pattern $[38,146,165,166]$. When the pile/cap configuration is asymmetric, the developing soil arching does not follow the 3D hemispherical dome shape depicted in Figure 6. Rather, for instance, as illustrated in Figure 7, for piles in the triangular configuration having a square pile cap, an upper-boundary semiellipsoidal shape accompanied by a lower-boundary semicircular arch would be found. In this approach, while the upper-boundary arch transfers the load onto the pile caps, the other one takes its portion towards the area between adjacent pile caps. In order to avoid further problem complexity, the model developed to obtain Figure 7 excluded consolidation and creep behaviour pertinent to both soft soil and geosynthetics. In the figure, $s$ stands for pile spacing, and $\mathrm{a}$ is the width of the square pile cap; thus, the gap between the boundary change approximately becomes half of a at the toe and 0.9 times the clear cap spacing (s-a) at the crown. With 3D numerical analysis, Wijerathna and Liyanapathirana [168] also showed the changes in the arch thickness for circular piles arranged in a triangular grid, but it was found that the $3 \mathrm{D}$-dome shape arch above the triangular grid of columns is shorter than the $3 \mathrm{D}$-dome shape arch above the square grid.

Pile spacing significantly affects the evolution of soil arching. In the first place, as explained by Roy and Bhasi [90], the arching phenomenon is not instantaneous, rather propagates from the construction phase to a certain degree of consolidation before it is fully developed. Secondly, as the spacing is increased, both arching effect and tensioning in the membrane reduce, consequently, decreasing the load taken by the piles. It is, then, accompanied by an increase in the stress borne by the foundation soil. In the process of developing the soil arch effect, as the relative displacement of the pile and soil continues, the initial increase in the axial force along the length of the pile tends to decrease in a certain way after a specific point. Associated with this relative movement between the pile and the surrounding soil, negative skin friction (NSF) develops in the upper part of the pile section. It is observed that the arching phenomenon and tension membrane effect reduce the developing NSF, and the NSF developing along the pile affects the performance of both geosynthetic-reinforced and conventional-piled reinforcement [77, 90, 169]. Cao and Zhao [77] found the distribution of NSF along the length of the end-bearing pile covered almost the entire length but was distributed in the upper one-third of the length of the floating piles. Meanwhile, as illustrated elsewhere, the deformable cushion layer defuses the foundation load indirectly to the pile creating NSF on the upper pile body. In this regard, the NSF developing in the upper pile section becomes a major load transfer factor.

The mobilized NSF is mainly governed by the cushion thickness and stiffness of both the cushion and the subsoil $[22,135,170]$. The greater the compressive modulus of the soil between the piles, the greater the stiffness and the more the soil shares the overlaying load; accordingly, the load carried by the pile body is relatively reduced. The effect of soil compressibility in this regard is well detected both theoretically and experimentally [23, 35, 171, 172]. The load applied on top of the cushion layer generates relative pilesoil displacement large enough to develop shear stresses along the pile-soil interface. As the load increases, the pile 


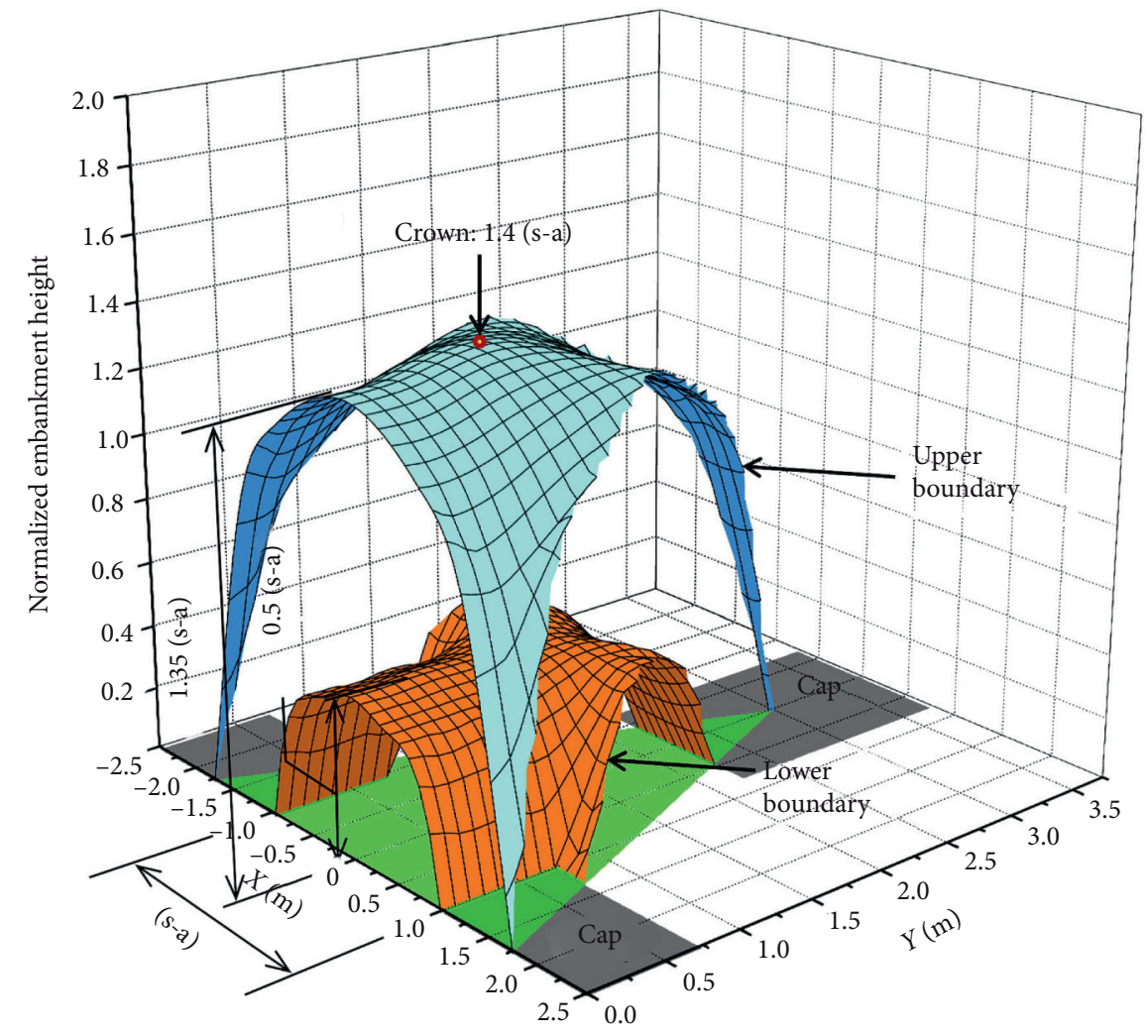

Figure 7: Three-dimensional soil arching for the triangular pattern pile arrangement [167].

compresses the cushion layer and continuously penetrates vertically until the cushion adjusts itself to arrive at a balanced state. At some specific load level, the upward puncture of the pile reverts to downward penetration into the subjacent soil. In addition, due to the difference in stiffness, the stress on the pile head becomes higher than that on the subjacent soil. Understanding this phenomenon led many scholars to envisage that a section existed where both the pile and the surrounding soil underwent equal settlement at the same depth [56]. The plane at this particular depth is called as a neutral plane. Conveniently, an ideal equal-strain boundary condition exists at the neutral plane [7, 171, 173]. For the section above this level, the upper pile part settles less than the soil in the vicinity. This produces NSF to mobilize along the shaft. However, for the depth below that equal settlement section, the lower pile part undergoes greater relative settlement than the soil so that positive skin friction (PSF) develops.

According to the centrifugal test of Fioravante [64], as the applied load on the composite foundation of a single rigid pile continues, the neutral plane moves upward from a depth near the middle of the pile. Wu et al. [23] verified the same and stated that the depth ratio of the neutral surface to the total pile length assumes a value ranging between 0.15 and 0.35 for a pile spacing five times the pile's diameter $D$. On the contrary, for pile spacing $4 D$, Dan et al. [171] reported the neutral surface to be located at a depth of $0.6 \sim 0.7 l$ of the pile body. This is consistent to the centrifuge model test result of Wang et al. [169] who reported the pile length ratio of $0.59 \sim 0.67$ for a spacing $4 D$, even though the range of the neutral plane location is higher than that deduced by Wu et al. [23]. This could be the result of a decrease in the relative pile-subsoil displacement as the pile length decreases [135]. However, the studies gave insight about the effect of pile spacing and reached on the same conclusion that, with the increase of pile pacing, the depth of the neutral surface moves deeper, as shown in Figure 8. This is because of the group effect. As piles are closely spaced in a group, the load carried by each pile decreases and so does the pile-soil stress ratio. Subsequently, the bearing capacity of the pile and the soil between piles could not be fully developed. If the pile spacing is increased, then the load borne by the individual pile will increase, and gradual full play of each pile and the soil between piles would become apparent. Accordingly, stress concentration occurs on the top of the pile, and the relative pile-soil displacement increases. In contrary to this, due to arching and tension membrane effects in GRPS embankments, an increase in the centre-to-centre pile spacing decreases the neutral plane depth, and the NSF also reduces [90].

Another interesting observation which can be made from Figure 8 is that the location of the neutral plane stays stable around a particular depth beyond a certain pile spacing. In addition to the change in the neutral surface depth with time under the working load, the literature also shows that the maximum NSF befalls on the upper part of the piles, accompanied by a relatively large pile-soil relative displacement [23, 29, 44, 121, 169]. Saeedi Azizkandi et al. [135] numerically indicated the decrease in NSF as the number of piles increased. They also showed that the central pile experienced the highest amount of NSF compared to the 


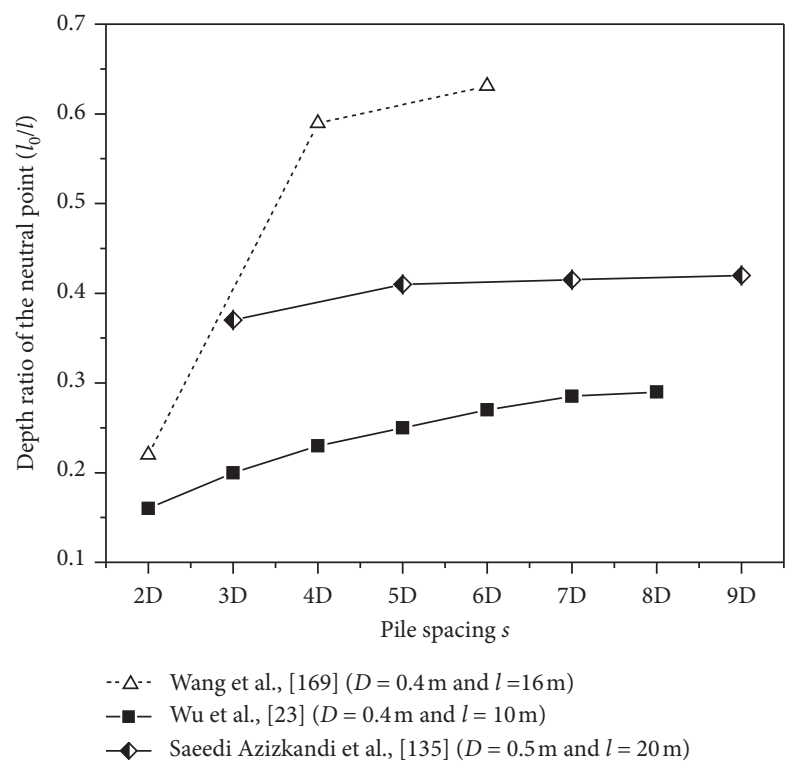

Figure 8: Variation of the neutral plane depth with pile spacing $[23,135,170]$.

rest in the group. Similar result was conveyed by Li et al. [55] from their experimental investigation using centrifuge test.

Available analytical methods to analyse the pile-soil stress ratio were often developed by assuming the pile maximum positive and negative frictional stress to either fully be mobilized up to the equal settlement section or partially mobilized in the transition zone around the neutral plane while fully achieved at the pile ends, as indicated in Figure 3(c). With the adoption of the first assumption (Figure 3(c)-I), the central elastic zone is neglected to simplify the calculation, in fact, based on previous observations that a small amount of relative pile-soil displacement is usually required to mobilize the ultimate shaft friction value, which is smaller than $5 \mathrm{~mm}$ in normal condition $[56,174-176]$. In the latter case (Figure 3(c)-II), the plastic state of the soil developing close to the top and bottom pile ends continues in the transition zone depending on the relative soil-to-pile displacement required to fully mobilize frictional resistance, according to equation (5) $[23,28,74,177]$. Then, the vertical equilibrium of the infinitesimal soil element of depth $d_{z}$ is considered taking into account the continuity and boundary conditions so that the compression deformation compatibility is implemented for the sections above and below the equal settlement plane to arrive at the expression for solving analytically the pile-soil stress ratio.

$$
\tau_{(z)}= \begin{cases}k_{s}\left|w_{s z}-w_{p z}\right|, & \text { for } 0 \leq w_{s z}-w_{p z}<u_{m} \\ \tau_{f}, & \text { for } w_{s z}-w_{p z} \geq u_{m}\end{cases}
$$

where $\tau_{(z)}$ is the skin friction along the pile shaft at a depth $z$, $k_{s}$ is the initial stiffness gradient of skin friction, $\tau_{f}$ is the ultimate pile side friction value, $w_{s z}$ is the settlement of the soil between piles at a depth $z, w_{p z}$ is the pile settlement at the same depth, $u$ is the relative pile-soil displacement, $u_{m}$ is the critical displacement corresponding to the pile-soil displacement difference when the pile side friction changes from the elastic state to the plastic state, $\delta_{t}$ and $\delta_{b}$ are the relative pile-soil displacement at the pile's head and tip, respectively, $P_{p}$ and $P_{s}$ are the stress borne by the pile and soil, respectively, and $\sigma_{s z}$ and $\sigma_{s z}+d \sigma_{s z}$ are the top and bottom stress on the soil slice, respectively; $l$ and $l_{0}$ were defined earlier.

The ultimate pile side friction resistance $\tau_{f}$ in the plastic state is related to the shear strength and effective stress of the soil around the pile, which can be calculated as follows:

$$
\tau_{f}=c+\sigma \tan \phi=c+k_{0}\left(\gamma z+\sigma_{s 0}\right) \tan \phi
$$

where $k_{0}=\tan ^{2}\left(45^{\circ}+\phi_{0}\right) / 2$ is the passive earth pressure coefficient of the soil, $\phi_{0}$ is the internal friction angle of the soil mass, $\phi$ is the friction angle of pile-soil, and $\sigma_{s 0}$ is the vertical stress of the soil surface between piles. For cohesionless soils, equation (6) reverts to $\tau_{f}=k_{0} \sigma_{s 0} \tan \phi$ $[23,178]$. It can also be considered that there is no horizontal offset between the pile and the soil, and the calculation is carried out according to the static earth pressure [171].

Under a combined action of vertical and horizontal loads, an increase in lateral load moves the position of neutral depth upward in the saturated soil medium [179]. This attributes to the greater pile-soil relative settlement as consolidation continues, so the pile body shows several neutral points. With the increase of lateral load, the shear band and displacement field of the soil continue to appear in the direction of load, and the friction force between the raft and the cushion increases accordingly. As a result, depending on the cushion thickness, the shear force at the pile head decreases, and the bending moment at the said location becomes nonnegligible $[114,127]$. Consequently, the horizontal load is carried by the frictional resistance developing at the contact surface between the cushion and the raft. Judiciously speaking, the overall horizontal bearing capacity is regulated by the minimum lateral resistance offered by each foundation part, i.e., the minimum of the 
lateral bearing capacity of the mat, the cushion, the interface between the cushion and the raft, or the frictional resistance developed at the interface of the cushion and pile-soil ground [114]. When CFG piles are used to reinforce the natural ground against liquefaction and as a foundation system in seismic regions, the cushion provides the same benefit to the base isolation systems [49, 117].

More importantly, due to unprecedented population growth and land scarcity in urban dwellings, new buildings are inevitably being built in close proximity with old ones supported by ground improvement technology. Understanding their interaction mechanism is as highly sought as investigating the effect of new construction activities on existing infrastructures found on common foundation types such as piles. In other words, the serviceability of the existing nearby CFG pile composite foundation is also affected by any new tunnelling and deep foundation pit excavationinduced ground deformations. While passive loading on the CFG pile composite foundation is implicitly discussed in embankment failure mechanisms (see the failure mode section), the complex interaction of such foundation system with their environment as a result of urbanization has got little consideration in previous studies.

The study on the interaction between new excavation and adjacent reinforced composite ground associates controlling excavation-induced ground movements to ensuring safety and stability of structures found on the reinforced composite foundation. Causative factors for the incidence of ground movement during excavation was a subject studied over the past decades [180-185]. Successful methods have been forwarded to decrease the acting force on retaining walls and consequently their displacement so that nearby structures and public utilities are protected from damages related to soil movements [186-188]. It is well known that the earth pressure exerted on the earth retaining structure actually depends on the distribution and amount of wall movement (rigid body translation, rotation, or/and deformation/deflection) as a function of the retaining wall type, ground condition of the retained mass, and applied external loads, of course, resulting in a certain amount of associated ground movements [189-194]. The following discussion is limited to investigations made on the interaction of the adjacent CFG pile composite foundation with excavation supported by two different retaining wall types-rigid and cantilever retaining walls.

According to the model test results of Wang and Yang [121], when an adjacent excavation work proceeds, continuous adjustment of the load borne by CFG piles will occur in a complex way of interaction, that is, among the pit retaining structure (pit supporting piles), CFG pile composite ground, and strip of the soil column between pit supporting piles and the CFG pile composite ground. Li et al. [119] on their experimental investigation using centrifuge test pointed out that prediction of excavation-induced lateral earth pressure on the retaining wall using the conventional Rankine method was so conservative when the backfill side was CFG pile composite ground (see Figure 9). The bottomup excavation done on three layers (at 2.4, 3.2, and $4.4 \mathrm{~m}$ depth progression from top to bottom) was retained by the pile raft, and the composite foundation was set at a distance of 0.16 times the depth of excavation. Due to the shielding effect of CFG piles, the reduction of active earth pressure was profoundly seen. To account the same while using the classical Rankine theory, they considered the change of axial pile load in equation (7). Their research finding provided an important direction for improving the economic benefits gained because of the shielding and reinforcing effect of CFG piles in design of the adjoining foundation pit-supporting structure.

$$
\sigma_{s z}= \begin{cases}\frac{\left.\left(p_{m}+\gamma z\right) s^{2}-N\right)}{A_{s}}, & \text { for } z \leq l, \\ p_{m}+\gamma z, & \text { for } z>l,\end{cases}
$$

where $\sigma_{s z}$ is the vertical stress at a depth $z$ from the pile head, $p_{m}$ is the foundation stress, $A_{s}$ is the bearing area of the soil between piles, given by $A_{s}=s^{2}-\pi D^{2} / 4, s$ is the pile spacing, unit weight of the natural foundation soil, $N$ is the measured pile axial load at a depth $z$, and $l$ is the pile length.

However, current specifications (e.g., the Chinese technical code for support of building foundation pit-DBJ 41/139-2014) for calculating the active earth pressure on the retaining wall for excavation of the foundation pit adjacent to the CFG pile composite foundation conservatively recommend to multiply the characteristic bearing capacity of the soil between piles by 1.2 to obtain an additional load on the bottom of the cushion and use this value as a surcharge when the pile end is below the bottom of the foundation pit. Otherwise, the common stress diffusion method is employed to calculate the additional stress value at the plane position of the pile tip before applying the Rankine earth pressure coefficient. This approach does not fully take into account the observations about the shielding and reinforcing effect of CFG piles [29].

Based on the experimental study conducted on the earth pressure evolutionary mechanism against the rigid retaining wall adjoining the rigid composite foundation at 0.1 times the excavation depth (D), Wei [29] also arrived at the same inference that the additional active earth pressure on the retaining wall is smaller than that of the natural foundation as shown in Figure 9. The figure compares the works of Wei [29] and Li et al. [119] who employed different excavation support structures, soil properties, and distances from the excavation edge under different surcharge loadings on the composite foundation. The work of Li et al. [119] simulated the process of excavation, but only the lateral pressure after the final excavation stage was presented here for space brevity. In addition, the lateral pressure predicted according to both the traditional Rankine earth pressure theory and the elastic solution for surcharge strip loading [191] is included as presented by the authors. On the left is depicted the lab setup of Wei [29], while the right one roughly represents the scenario of Li et al. [119]. It can be easily observed that the presence of vertical reinforcing columns in the composite foundation made the lateral active pressure acting on the retaining wall to be less than the value obtained using conventional algorithms. The study of Wei [29] also pointed 


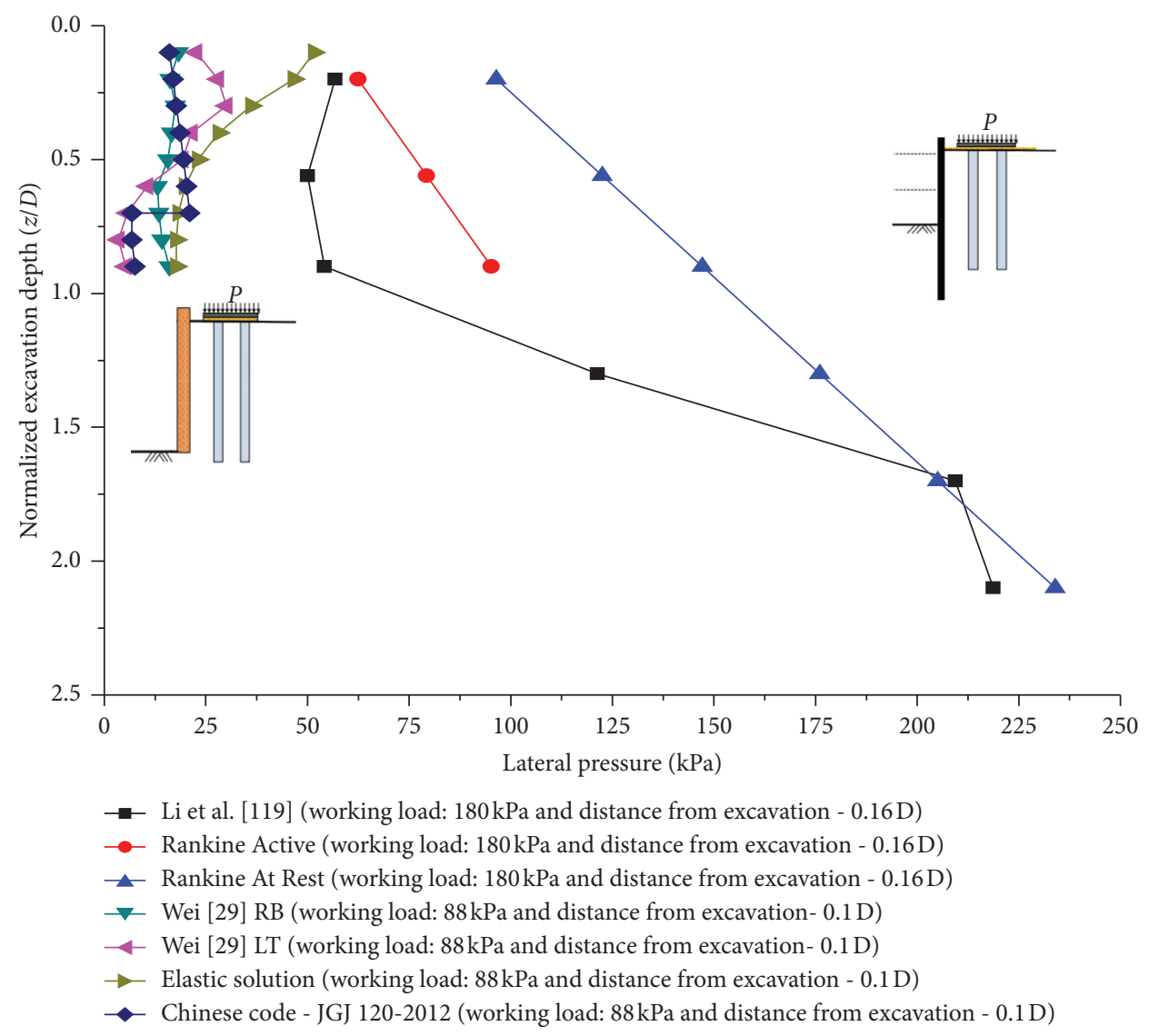

Figure 9: Lateral earth pressure distribution along retaining wall depth (modified after Wei [29]-left; Li et al. [119]-right).

out that the shielding effect of the composite foundation was more pronounced in the depth range of negative friction developed along the pile length. Somehow, after a certain depth below the neutral plane, due to the positive frictional force, the additional stress on the wall within that depth range begun to increase approaching to the measured static earth pressure as the wall rotated about its base (RB). The increase in earth pressure at the bottom of the wall is attributed to the small displacement that does not allow the full active state to be reached. It is to be reminded that the elastic solution assumes complete active state is achieved. In addition, due to the presence of piles, it has been shown that the soil sliding surface behind the wall is different from the conventional failure slip surface (see Figure 10).

As the wall moves away from the composite ground in the translation mode (LT) or rotation around its base (RB), the pile begins to bear additional loads. Figure 11 illustrates the variation of pile head load sharing during wall movement. Owing to the subsequent movement of the soil as the wall underwent a certain amount of displacement away from the reinforced soil, the load bearing capacity of the soil between the piles decreased, and the load shared by the piles correspondingly increased.

In order to further understand the effect of foundation pit excavation process on the response of nearby CFG piles, the centrifuge experimental work of Li et al. [119] was further studied $[195,196]$. The distribution of axial load, bending moment, and deflection of the CFG pile during each excavation stage at different locations of the $6 \times 4$ pile group subjected to $180 \mathrm{kPa}$ working load were discussed, but for the sake of space brevity, only the axial force variation is presented here in Figure 12. Figure 12 shows the axial force distribution of the monitored CFG pile located at a distance of $12 \mathrm{~m}$ (i.e., at the middle of the group) behind the $10 \mathrm{~m}$ deep excavation. The edge of the excavation was at $2.0 \mathrm{~m}$ away from the first row of piles. As can be seen from the axial force evolution in both loading process and foundation pit excavation stages, the increase in the axial force manifested a vertical load transfer mechanism with an increasing trend, which showed the continuation of the increase in the pile-soil stress ratio due to the process of excavation, even though it was not significant in the earlier excavation stages. In this particular experimental work, the reason for the deeper neutral axis was probably the lower coefficient of friction between the pile and the soil, which is yet to be verified with future testing. Moreover, as expected upon the last excavation, the soil stress relief and lateral displacement became greater. Consequently, the resulting increase in the overall and relative pile-soil settlement influenced more the response of the piles closest to excavation than the others.

According to the numerical analysis of Ren and Qiao [197], an increase in the excavation depth increases the 


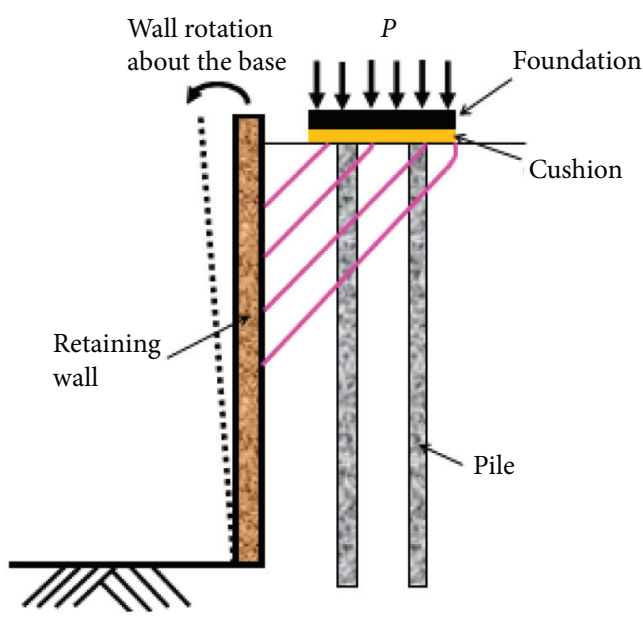

(a)

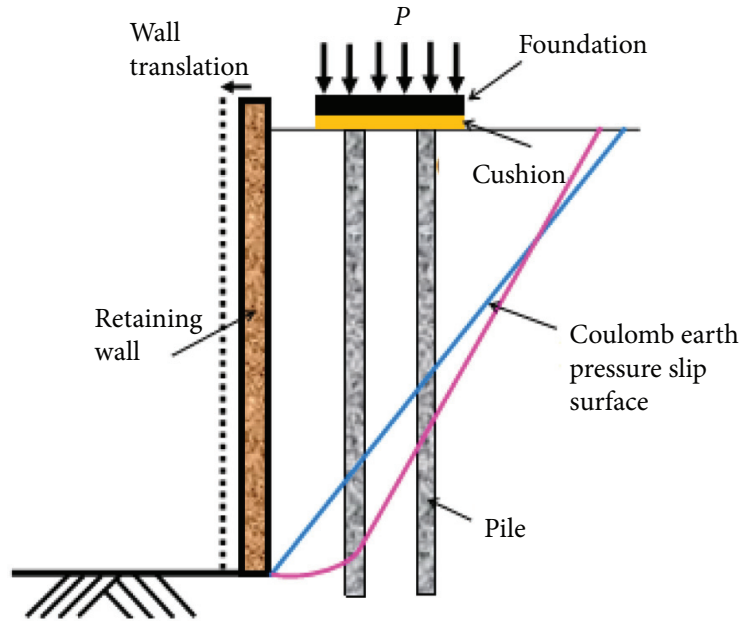

(b)

Figure 10: Potential failure surface in the soil behind a retaining wall under (a) rotation about its base and (b) translational mode [29].

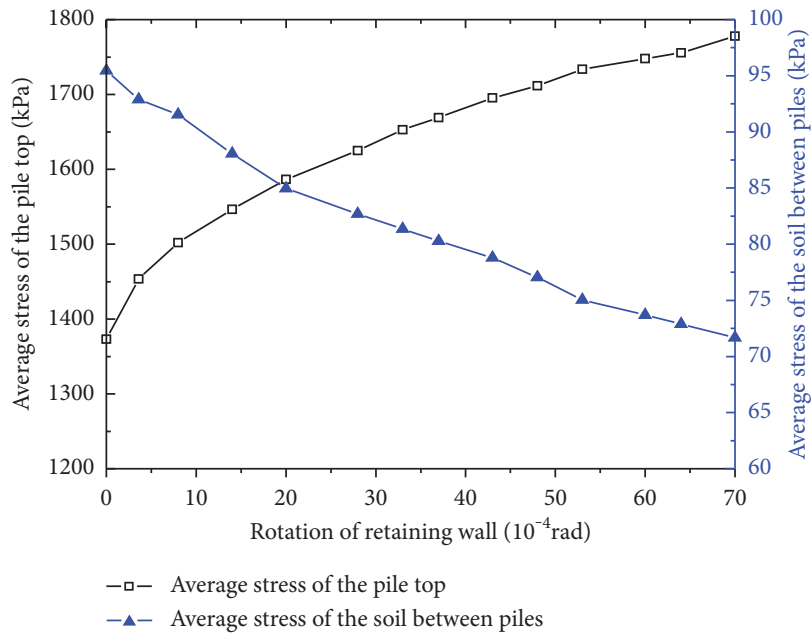

(a)

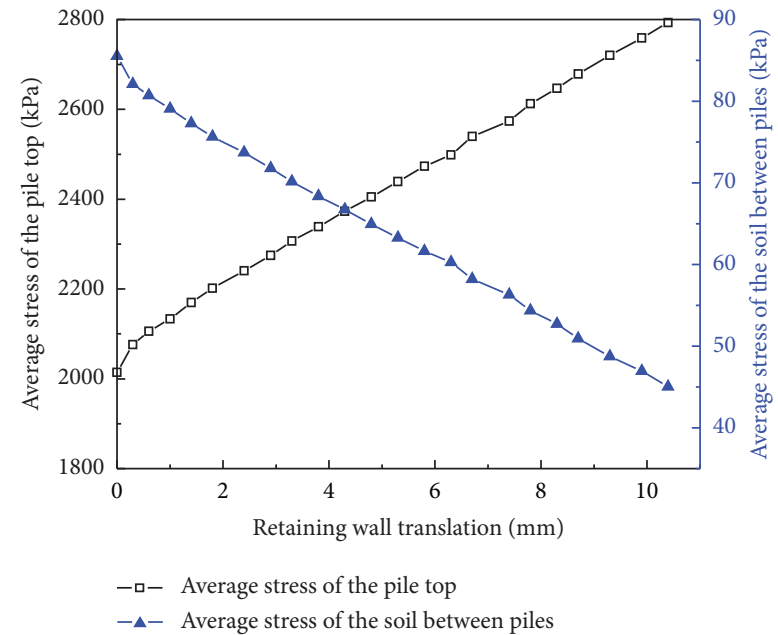

(b)

FIGURE 11: Influence of retaining wall movement on the average stress of the soil between piles and the pile head of the composite foundation under a working vertical load of $88 \mathrm{kPa}$ : (a) rotation about the base; (b) under the translation mode [29].

lateral displacement of the CFG piles. On the contrary, on the basis of previous research on the conventional pile foundation under passive load, the impact of axial working load on the lateral pile response is not significant, but once the serviceability limit is exceeded, unperceivable sudden failure and collapse may occur [198, 199]. To better apprehend this risk in CFG pile composite foundations under working load, further investigation is needed on excavationinduced lateral pile displacement and developing sectional bending moments.

In practice, when unexpected project threats appear in the presence of a wide range of geotechnical design and construction uncertainties, Peck's observational method $(\mathrm{OM})$ has been proven to be effective in addressing deviations from preconstruction behaviour as construction progresses [200-203]. The OM, later amended as observational modelling, uses inverse analysis and sound engineering judgment to recalibrate monitored actual conditions and attack unfavourable ones through "progressive modification" during project implementation without compromising safety. Yet, this model itself has some remaining reticence for its wider use [204].

4.3. Failure Modes. In order to provide theoretical and numerical solutions to problems regarding stability and integrity of the foundation system as a whole, numerous research articles presented implicitly or explicitly the failure pattern analysis. For clarity, the following briefing is made separately on possible failure modes of the cushion, pile, and potential failure mechanism in embankments. 


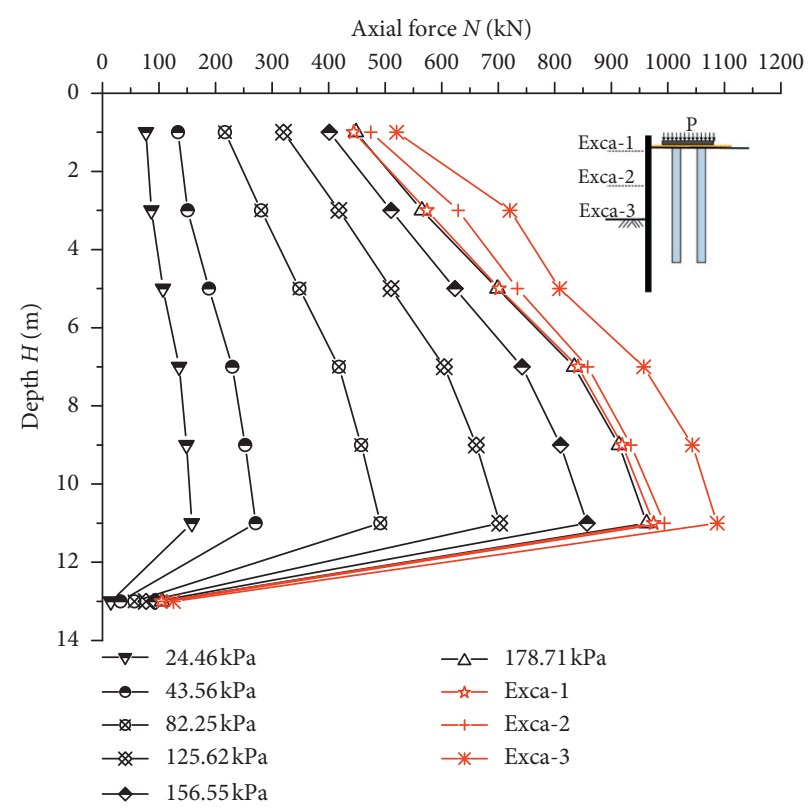

Figure 12: Distribution of the monitored axial force during loading and excavation stages [195].

4.3.1. Failure Mode of the Cushion. As previously discussed elsewhere about the load transfer mechanism, the pile head pierces into the cushion, while the cushion adjusts itself to redistribute the load. This penetration process generates high stress concentration and plastic zone development propagating from the side of the pile head as the cushion is compressed with higher stiffness bodies at its upper and lower boundaries [33]. Accordingly, depending on the cushion thickness, scholars have found that the stress and displacement fields resemble an inverted pile on the foundation soil. Thus, the failure mode may take three forms: overall shear failure, local shear failure, and punching shear failure [151, 205]. Zhu [206] experimentally examined the effect of gradation on the slip surface and found the general shear failure mode for a gravel cushion while local shear failure for fine gravels having the same cushion thickness. However, from practical engineering experience under normal loading condition, the thickness of the cushion layer is far less than that required for Terzaghi's failure mode to occur; thus, the Mandel and Salencon failure mode is usually used to theoretically propose design cushion thickness [207]. Supporting the same after their numerical analysis, Dong et al. [208] argued that failure mode discussions for the cushion were unnecessary due to the strong bearing capacity it had relative to the weak underlying soil. In the concept of rigid inclusion with the thin load transfer platform, the two possible failure mechanisms in the guidelines of the ASIRI are Prandtl's and punching shear failure modes [152]. Under the cover by rafts or sufficiently thick embankments, the ultimate limit state consideration prudently satisfies the stress domain to remain within Prandtl's limit state before internal failure of the cushion occurs [209].

4.3.2. Failure Mode of the Pile. The failure mechanism for piles may assume many possible failure modes depending on the imposed loads. Under vertical loading, the pile may crush, bulge, fail in bearing at its head, and/or short floating pile may undergo punching. If piles are subjected to passive horizontal loading resulting from adjacent excavation or embankment, depending on strength, diameter, and pile location, either rupture breaking failure (structural failures due to shear, bending, and tensile strains, e.g., $[7,127,179]$ ), soil flow around the pile, pile rotation, translation, and/or collapse pattern of piles as a whole may occur [210-213]. Among the cases for passive loading, failure under embankment loading condition is summarized in the following.

4.3.3. Failure Mechanism in Embankments. Instability of embankments supported by the CFG pile composite foundation has been discussed in enormous literature studies [78, 213-215]. The failure pattern normally depends on the strength of the piles, and applying the slip-circle analysis for stability of the improved subgrade needs cautions under practical conditions [212, 216-218]. For the CFG pile-net composite foundation, Jiang and Wang [147] numerically described four failure patterns (viz. slip-circle shear failure, pile tilting, subgrade sliding, and soil sliding at the pile end) based on embankment deformation and subsoil layers. They implicitly showed that depending on the location of the pile, piles undergone an arc-like deformation, whereby plastic hinge formation occurred in the active zone as explained by Yapage et al. and Broms [212, 219]. The deformed piles shaped like concave towards the embankment slope under the effect of the geogrid, but in the absence of the geomembrane, the arc bulged outwards $[214,215]$. The common failure mode in the latter case was reported to be pile bending and collapse. According to Kitazume [218], from the stability point of view under higher-strength piles, the area replacement ratio has a dominant effect, and failure is expected to occur in a collapse failure mechanism. 


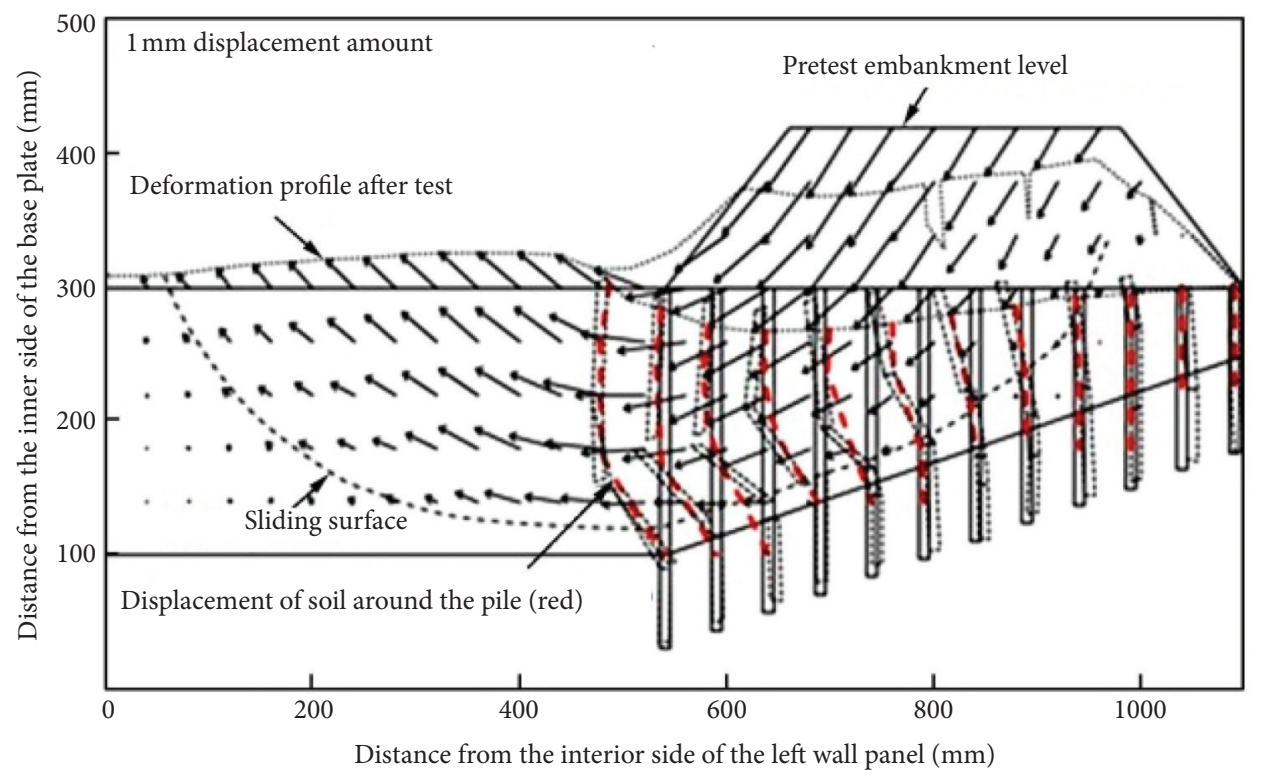

Figure 13: Asymmetrical deformation field and the failure mechanism of the CFG pile-supported embankment on the inclined soft foundation [78].

Of the above problems, Zheng et al. [213] disclosed that piles at the centre of the embankment endured smaller bending moment than the others. Their centrifuge test also demonstrated that piles may fail with secondary bending in the upper part depending on the stiffness and embedment depth into the stiff layer. Dependency on the location of piles was also observed by other scholars and may lead to combined failure mechanism $[210,217,220]$. Chen et al. [217] recommended an exterior row of columns at the edge of the slope to provide extra lateral soil resistance to edge piles. For embankments on the inclined soft foundation, $\mathrm{Gu}$ et al. [78] experimentally showed the soil deformation and CFG pile fracture to be concentrated in the downhill direction, see Figure 13. As can be noted from Figure 13, the pile breaks at the interface of the soil layer, and the more approached to the toe of the slope, the greater the degree of pile fracture and displacement will be.

4.4. Construction Practices and Quality Assurance. Although the CFG pile composite foundation has wide applications due to its short construction period and cost-effectiveness, undesirable qualities and failure to satisfy quality requirements have been encountered during inspections. For example, Hang [221] analysed causes of pile necking. According to Teng [222], the construction operation and ontime removal of wastes generated by piling had significant issues on just constructed pile head fractures. Ren and Shi [223] reported that the bearing capacity of some CFG piles failed to meet the design requirement during inspection. Thus, it is very important to control the quality of CFG piles. Being a concealed underground work, the CFG pile quality shall be continuously monitored throughout the construction process [224]. The level of contractor's quality management system and supervisor's quality inspection follow-up plans integrate (1) the workmanship, machinery, and technology deployed, (2) effective supply chain, (3) safety considerations, etc. which the contract document entails. As the project construction goes on, quality assurance reflects a process that is not meant for "hunting the guilty" through stringent contractual conditions but to assure performance compliance and specification requirements are timely met. The construction process basically starts off from selecting appropriate construction technology and the sequence of construction suitable for the field condition. It has to minimize possible soil disturbance between piles, noise, and dust pollution during piling. To this end, machinery technology is usually deployed through either vibrating tube-sinking (in silt and cohesive soils) or long spiral drilling method-bored perfusion cast in situ pile (in clays, silts, and dense and medium sand above the groundwater level) or concrete pumped (for strict pollution control), in which the piling order may follow continuous or alternate (interval jump) installation sequence $[2,5,148]$. The piling sequence may affect the quality of installed piles (squeezing, necking, or crushing and fracture damages) depending on the type of soil as the piling proceeds [6].

The construction process typically follows the flow in Figure 5. After the concrete mix is carried out with the approved material according to the contract specification, 
the concrete is continuously poured into the hole dug to the design elevation. While concreting in the water-bearing stratum, the pile pipe shall not be pulled out immediately in order to have better concrete quality as well as to avoid pipe plugging. Then, withdrawal can proceed at a controlled speed of less than $1.2 \mathrm{~m} / \mathrm{min}$, preferably $0.6 \sim 0.8 \mathrm{~m} / \mathrm{min}$ to prevent pile fracture and hole shrinkage $[148,149]$. Once pile construction is finalized, field static loading test is carried out on an inspection batch piled on the same day (the ratio of the spot test number to the total pile under consideration being $0.5 \sim 1 \%$ ) after 28 days of curing period based on the low strain wave velocity and time-history relationship $[1,149]$. Using the low strain dynamic test, the supervisor assures the quality of the pile body and its structural integrity as to whether defects exist or not that may affect the bearing capacity eigenvalue such as pile-end concrete segregation that reduces the end resistance [223]. It is recommended to install new piles a week after the old ones [225].

\section{Remarks and Future Research Directions}

Regardless of how much we know in any field, yet there exist new things to explore. In the quest to grasp development trends and theoretical research advances to meet the needs of engineering practice, it was found that the CFG pile composite foundation has addressed both soft ground improvement and green environment construction issues. Nevertheless, the following research gaps have been spotted.

The discrepancy between calculated values for the bearing capacity according to code requirements and those measured from field tests still deserves further assessment to address questions such as is the difference because of far less number of test piles than calculation piles? Or is it due to uneven soil distribution encountered while testing? Or is it due to the increase in side resistance while testing? Moving on, a more rigorous theoretical approach is needed to account for soil nonlinearity and stress path-dependent characteristics during settlement predictions. Likewise, both static and dynamic characteristics of the multipile composite foundation composed of the CFG pile and other pile types are not well understood.

In the early attempts, however, little emphasis was given on the effect of heat disturbance as compared to the foundation strength and deformation requirement. On the one hand, the heat exchange performance under alternating heating condition is sought [226], while on the other hand, the behaviour of CFG piles in the permafrost environment is getting attention [18, 227]. To better understand the resistance to cycles of freezing and thawing process, further study is needed.

For adjacent excavation activities, the load transfer mechanism and excavation-induced settlement can further be explored through parametric studies by varying some factors such as excavation supporting system stiffness, the process of excavation, distance from the excavation, the formation level relative to the CFG pile toe, the pattern of soil movement (magnitude and distribution profile) along the depth, interpose layer characteristics and thickness, engineering properties and drainage condition of the retained soil, piles' arrangement and spacing, pile length considering hybrid piles (various types and dimensions), replacement ratio, and working load. Moreover, from the probabilistic analysis point of view, its behaviour under complex geological conditions is still unclear [21]. In order to capture the soil-structure interaction while simulating the excavation process using model tests, adopting advanced technologies to directly measure the response of each component during the experiment is essentially sought; nonetheless, in the current experimental setup, consideration to account for factors such as superstructural stiffness and the influence of retaining wall installation during soil filling still lags behind perfection [228-230].

Another increasing interest lays on issues with GRPS embankments. One issue is the soil-arching phenomenon. It was found that the modern $2 \mathrm{D}$ trapdoor test needs validation with 3D or field tests [231]. Along with it, the influence of trapdoor's rigidity and shape on arching is yet to be explored. The same goes regarding the influence of loading condition (uniform, localized, or cyclic and seismic) on soil arching. On the contrary, it certainly becomes noteworthy to promote studying the complex construction processes and long-term performance such as creep and stress recovery.

In addition, future study may be needed regarding the failure mechanism of CFG piles under the combined failure mode. This may be required in order to resolve the question about how gradually or suddenly the failure of piles develops, whether it happens simultaneously or not to all piles, and the specific cause of the pile fracture caused by tension, bending, or shearing.

\section{Conclusions}

The paper looks back over the development and engineering applications of the CFG pile composite foundation. Even though more concentration was made on the load transfer mechanism, sections were devoted to its economic appraisal, possible failure mechanism, construction practices, and quality assurances during inspections. The findings are summarized as follows.

For superstructures supported by the CFG pile composite foundation, the key engineering achievement was to bring marginalized natural soft ground into full play in supporting foundation loads. The deformable load distribution layer between the raft and the pile generates high nonlinearity in the system and, hence, creates a complex load-sharing phenomenon to make the pile and soil work together and adjust the pile-soil stress ratio. The cushion thickness, frictional characteristics, and stiffness likely control the load transferred to piles through the head and negative shaft friction. The neutral depth location is dependent on, but not limited to, the subsoil stiffness, the cushion properties and thickness, the pile spacing, pile length, replacement ratio, and location of the pile in the group. These parameters in turn affect the pile-soil stress ratio.

In practice, $\mathrm{CFG}$ pile composite foundation will bear not only vertical pressures but also horizontal loads. When they are subjected to horizontal loading, their lateral bearing 
capacity is normally obtained from the frictional shearing resistance mobilized between the mat and the interposed layer. However, judicious assessment may be necessary to check whether or not the lateral ultimate bearing capacity of each part is exceeded. Even though the shear force at the pile heads was found to decrease as the cushion thickness increases, the frictional resistance developed at the interface of the cushion and pile-soil ground may control the overall lateral capacity if it is less than the lateral resistance offered by the lateral bearing capacity of the mat, the cushion, or the interface between the cushion and the raft. When CFG piles are subjected to passive loading from adjacent excavationinduced ground movements, a complex interaction arises among the excavation supporting structure and the existing composite foundation. The excavation activity just adds complexity to the already intricate soil-structure interaction problem as the foundation continuously adjusts the pile-soil stress ratio. Moving on, both the active lateral earth pressure exerted on the retaining wall and the failure surface for the natural soil between piles differ from the conventional solution. Albeit indoor tests with advanced technologies which are capable of directly measuring the response of constituent structural elements could be used to simulate the excavation process, and the current experimental setup still lags behind perfection to consider factors such as superstructural stiffness and the influence of retaining wall installation during soil filling. Thus, full understanding of the behaviour under passive loading remains to be an opportunity for further investigations.

For embankments constructed over CFG pile-reinforced subgrade soil, due to stiffness differences, arching phenomenon develops, and piles attract larger load proportion, whereas the natural ground bears approximately uniform pressure distribution. The major portion of the load is transferred through arching. When geosynthetic reinforcement is included, strips of geomembranes between piles become stiffer than those in the middle. This allows the reinforcement strips to receive a larger portion of the load than elsewhere with an inverse triangular distribution pattern. Depending on the pile configuration, the developing arch may establish a concentric 3D hemispherical dome shape or semiellipsoidal upper boundary accompanied by a semicircular lower-boundary arch. Arching phenomenon is not instantaneous but develops fully after a certain amount of consolidation. Compared to the apparent load transfer mechanism through cushions under rigid structural elements, the load transferred through negative friction in GRPS embankments is lesser due to arching and membrane effect. In this regard, further research is needed to understand the time effect of soil-arching development, the influence of the construction process, the effect of the localized load distribution, and cyclic loading on soil arching. Yet to be given further consideration is the long-term performance of geosynthetic-reinforced CFG-piled embankments.

As far as the failure mode in an isolated CFG pile is concerned, it is found that crushing, bulging, shear, and/or punching would occur on the top part of the pile. The quality of the upper pile body is affected by the method and sequence of construction. Consequently, close on-site operational assessment and continuous quality inspections are needed throughout the process of construction. The thickness of the cushion layer and the nature of the foundation above it determine the apparent failure mechanism developing in the load transfer platform. For a relatively thick cushion beneath the rigid foundation (such as mat or slabs on grade), Prandtl's failure mechanism takes place. If the cushion is covered by the flexible foundation (such as thin embankments), then punching shear failure mode develops. For a group of piles, pile bending and collapse were identified as common failure modes for internal stability in embankments supported by the CFG pile composite foundation. However, depending on the stiffness of firm stratum, area replacement ratio, stiffness and location of the piles, pile spacing, height of the embankment, and inclination of the soft ground bottom, a combined failure envelope may trigger. From a practical point of view, numerical analysis is usually employed to check stability and potential failure mechanisms.

\section{Conflicts of Interest}

The authors declare that there are no conflicts of interest regarding the publication of this article.

\section{Acknowledgments}

The authors gratefully acknowledge the support of Zhengzhou University's Presidential Scholarship Program for sponsoring the research area "Foundation Treatment and Foundation Pit Support Engineering."

\section{References}

[1] J. Chen, W. Chen, K. Zhang, and L. Li, “The application of CFG pile composite foundation in the reconstruction of the Dujiangyan," IOP Conference Series: Earth and Environmental Science, vol. 300, Article ID 022159, 2019.

[2] Q. Shen, L. Liu, and J. Yuan, "Study on design and engineering application of CFG pile composite foundation," Bol Téc, vol. 55, pp. 24-33, 2017.

[3] X. Shuo and W. Yunxia, "Research progress and development of CFG pile composite foundation," Applied Mechanics and Materials, vol. 353-356, pp. 706-710, 2013.

[4] D. Zhang, Y. Zhang, C. W. Kim et al., "Effectiveness of CFG pile-slab structure on soft soil for supporting high-speed railway embankment," Soils and Foundations, vol. 58, no. 6, pp. 1458-1475, 2018.

[5] Z. Zhao, B. L. Hallanger, Z. Shi et al., "Design discussion and construction quality management of CFG pile," International Journal of Services Sciences, vol. 5, pp. 529-536, 2013.

[6] S. Li, B. Yan, H. An et al., "Causes and processing methods for quality defects of soft foundation reinforcement using CFG piles," Chinese Journal of Geotechnical Engineering, vol. 39, pp. 216-219, 2017.

[7] J. Han, "Recent research and development of ground column technologies," Proceedings of the Institution of Civil Engineers-Ground Improvement, vol. 168, no. 4, pp. 246-264, 2015.

[8] J. Castro and C. Sagaseta, "Deformation and consolidation around encased stone columns," Geotextiles and Geomembranes, vol. 29, no. 3, pp. 268-276, 2011. 
[9] P. Jamsawang, D. Bergado, A. Bandari, and P. Voottipruex, "Investigation and simulation of behavior of stiffened deep cement mixing (SDCM) piles," International Journal of Geotechnical Engineering, vol. 2, no. 3, pp. 229-246, 2008.

[10] S.-L. Shen, J. Han, and Y.-J. Du, "Deep mixing induced property changes in surrounding sensitive marine clays," Journal of Geotechnical and Geoenvironmental Engineering, vol. 134, no. 6, pp. 845-854, 2008.

[11] C. J. Serridge and O. Synac, "Ground improvement solutions for motorway widening schemes and new highway embankment construction over soft ground," Proceedings of the Institution of Civil Engineers-Ground Improvement, vol. 11, no. 4, pp. 219-228, 2007.

[12] H.-Y. Jeon, "Geotextile composites having multiple functions," in GeotextilesElsevier, Amsterdam, Netherlands, 2016.

[13] Z. Song, H. Xiao, and Y. Zhao, "Hydrophobic-modified nano-cellulose fiber/PLA biodegradable composites for lowering water vapor transmission rate (WVTR) of paper," Carbohydrate Polymers, vol. 111, pp. 442-448, 2014.

[14] H. Huang, L. Mao, Z. Li et al., "Multifunctional polypyrrolesilver coated layered double hydroxides embedded into a biodegradable polymer matrix for enhanced antibacterial and gas barrier properties," Journal of Bioresources and Bioproducts, vol. 4, pp. 231-241, 2019.

[15] M. Daria, L. Krzysztof, and M. Jakub, "Characteristics of biodegradable textiles used in environmental engineering: a comprehensive review," Journal of Cleaner Production, vol. 268, Article ID 122129, 2020.

[16] W. Jiang and Y. Liu, "Determination of neutral plane depth and pile-soil stress ratio of the rigid pile composite foundation," Rock and Soil Mechanics, vol. 39, pp. 4554-4560, 2018.

[17] F.-Y. Liang, L.-Z. Chen, and X.-G. Shi, "Numerical analysis of composite piled raft with cushion subjected to vertical load," Computers and Geotechnics, vol. 30, no. 6, pp. 443-453, 2003.

[18] J. Liu and Y. Jia, "Temperature analysis of CFG pile composite foundation in high latitudes and low altitude island permafrost," International Journal of Structural Integrity, vol. 10, no. 1, pp. 85-101, 2019, https://doi.org/10.1108/IJSI07-2018-0045.

[19] Y. Shen and H. Wang, "Optimization design on CFG-pile foundation with different cushion thickness in beijingshanghai high-speed railway," Transportation Infrastructure Geotechnology, vol. 3, no. 1, pp. 3-20, 2016, https://doi.org/ 10.1007/s40515-015-0026-7.

[20] Q. Teng, X. Yao, S. Li, and J. Guan, "Finite element analysis of bearing capacity on the composite foundation of group pile," IOP Conference Series: Earth and Environmental Science, vol. 304, 2019 https://doi.org/10.1088/1755-1315/304/ 3/032061, Article ID 032061.

[21] X. Z. Wu and J.-X. Xin, "Probabilistic analysis of site-specific load-displacement behaviour of cement-fly ash-gravel piles," Soils and Foundations, vol. 59, no. 5, pp. 1613-1630, 2019, https://doi.org/10.1016/j.sandf.2019.07.003.

[22] V. Fioravante and D. Giretti, "Contact versus noncontact piled raft foundations," Canadian Geotechnical Journal, vol. 47, no. 11, pp. 1271-1287, 2010, https://doi.org/10.1139/ T10-021.

[23] C. Wu, W. Guo, and Y. Li, "Calculation of neutral surface depth and pile-soil stress ratio of rigid pile composite foundation considering influence of negative friction,"
Chinese Journal of Geotechnical Engineering, vol. 38, pp. 278-287, 2016.

[24] H. Chen and Y. Li, "Experimental study on load transfer law of rigid pile-raft composite foundations," Modelling, Measurement and Control C, vol. 78, no. 2, pp. 225-241, 2017.

[25] A. T. Ghalesari and H. Rasouli, "Effect of gravel layer on the behavior of piled raft foundations," in Advances in Soil Dynamics and Foundation EngineeringAmerican Society of Civil Engineers, Shanghai, China, 2014.

[26] H. Rasouli, A. Taghavi Ghalesari, M. Modarresi, and A. Hasanzadeh, "Numerical study of non-contact piled raft interaction under static loads," in Civil Engineering and Urban PlanningWorld Scientific, Xi'an, China, 2017.

[27] V. J. Sharma, S. A. Vasanvala, and C. H. Solanki, "Behaviour of load-bearing components of a cushioned composite piled raft foundation under axial loading," Slovak Journal of Civil Engineering, vol. 22, no. 4, pp. 25-34, 2014.

[28] L. Miao, F. Wang, and W. Lv, "A simplified calculation method for stress concentration ratio of composite foundation with rigid piles," KSCE Journal of Civil Engineering, vol. 22, no. 1, pp. 1-8, 2018.

[29] Y. Wei, Research on evolutionary mechanisms and calculation method of earth pressure against rigid retaining walls close to rigid composite foundation, Ph.D. Dissertation, Zhengzhou University, Zhengzhou, China, 2018.

[30] S. G. Huang, "Study on the bearing behavior of CFG composite foundation," in Rock Mechanics: Achievements and Ambitions, M. Cai, Ed., Taylor \& Francis Group, London, UK, 2012.

[31] H. Zhang and M. L. Shi, "Mechanical performance of settlement-reducing pile foundation with cushion," Advanced Materials Research, vol. 368-373, pp. 2545-2549, 2011, https://doi.org/10.4028/www.scientific.net/AMR.368-373. 2545.

[32] J. Lai, H. Liu, J. Qiu et al., "Stress analysis of CFG pile composite foundation in consolidating saturated mine tailings dam," Advances in Materials Science and Engineering, vol. 2016, Article ID 3948754, 12 pages, 2016.

[33] F. Tradigo, F. Pisanò, and C. di Prisco, "On the use of embedded pile elements for the numerical analysis of disconnected piled rafts," Computers and Geotechnics, vol. 72, pp. 89-99, 2016.

[34] R. Rui, J. Han, Y. Ye et al., "Load transfer mechanisms of granular cushion between column foundation and rigid raft," International Journal of Geomechanics, vol. 20, Article ID 04019139, 2020.

[35] S. Boussetta, M. Bouassida, A. Dinh, J. Canou, and J. Dupla, "Physical modeling of load transfer in reinforced soil by rigid inclusions," International Journal of Geotechnical Engineering, vol. 6, no. 3, pp. 331-342, 2012.

[36] S. Boussetta, M. Bouassida, and M. Zouabi, "Assessment of observed behavior of soil reinforced by rigid inclusions," Innovative Infrastructure Solutions, vol. 1, p. 27, 2016.

[37] P. Bui, Q. Luo, L. Zhang, and M. Zhang, "Geotechnical centrifuge experiment model on analysis of pile-soil load share ratio on composite foundation of high strength concrete pile," in Proceedings of the International Conference on Transportation Engineering, pp. 3465-3470, American Society of Civil Engineers, Southwest Jiaotong University, Chengdu, China, 2009.

[38] Y. Li, D. Zhang, and C. Wu, "Sensitivity study of the bearing capacity and pile-soil stress ratio for aeolian sand foundation treated with CFG piles," Revista Técnica de la Facultad de Ingeniería Universidad del Zulia, vol. 39, pp. 124-135, 2017. 
[39] Y. Gao, H. M. Li, and J. L. Yao, "Design research and technical application of the multi-type-pile composite foundation," Applied Mechanics and Materials, vol. 170-173, pp. 110-114, 2012, https://doi.org/10.4028/www.scientific. net/AMM.170-173.110.

[40] K. Liu, X. Xie, and H. Liu, "Performance of rigid-flexible-pile foundation with cushion," Proceedings of the Institution of Civil Engineers-Geotechnical Engineering, vol. 163, no. 4, pp. 221-227, 2010, https://doi.org/10.1680/geng.2010.163.4. 221.

[41] V. J. Sharma, S. A. Vasanvala, and C. H. Solanki, "Study of cushioned composite piled raft foundation behaviour under seismic forces," Australian Journal of Civil Engineering, vol. 13, no. 1, pp. 32-39, 2015, https://doi.org/10.1080/ 14488353.2015.1092636.

[42] R. Song, L. Lang, and J. Wang, "Application of long-shortpile composite foundation of high-rise building in soft soil," Applied Mechanics and Materials, vol. 256-259, pp. 57-60, 2013.

[43] J.-J. Zheng, S. W. Abusharar, and X.-Z. Wang, "Three-dimensional nonlinear finite element modeling of composite foundation formed by CFG-lime piles," Computers and Geotechnics, vol. 35, no. 4, pp. 637-643, 2008, https://doi. org/10.1016/j.compgeo.2007.10.002.

[44] E. Zhang, L. Yu, and X. He, "Analysis of action mechanism for rigid flexible pile composite foundation," Revista Técnica de la Facultad de Ingeniería Universidad del Zulia, vol. 39, no. 11, pp. 260-270, 2016.

[45] X. Ge, B. Li, and Z. Hu, "Application and analysis of longshort-pile composite foundation of high-rise building in soft soil," Build Structure, vol. 39, pp. 114-116, 2009.

[46] H. Lu, Q. Gao, B. Zhou et al., "Experimental research on bearing capacity of long-and-short pile composite foundation," Chinese Journal of Underground Space and Engineering, vol. 11, pp. 56-63, 2015.

[47] S. Hou, Research on force transmission mechanism and design theory of rigid long-short pile composite foundation, Ph.D. Dissertation, Zhengzhou University, Zhengzhou, China, 2020.

[48] J.-J. Zheng, S. W. Abusharar, and C. He, "Design theory and application of CFG-lime pile composite ground," in Proceedings of the 6th International Conference on Ground Improvement Techniques, Coimbra, Portugal, 2005.

[49] M. Zhang and X. Zhang, "A field experimental study of composite foundation with CFG pile + vibro-replacement stone column pile in liquefaction area," in Proceedings of the 2017 2nd International Symposium on Advances in Electrical, Electronics and Computer Engineering (ISAEECE 2017), Atlantis Press, Guangzhou, China, 2017.

[50] Q.-n. Chen, M.-h. Zhao, G.-h. Zhou, and Z.-h. Zhang, "Bearing capacity and mechanical behavior of CFG pile composite foundation," Journal of Central South University of Technology, vol. 15, no. S2, pp. 45-49, 2008, https://doi. org/10.1007/s11771-008-0434-8.

[51] S.-H. Ye and X.-N. Gong, "Static load test of a project CFG pile composite foundation," Mechanics and Architectural Design, pp. 175-180, 2016.

[52] F. Yan and X. Huang, "Experiment research of bearing behavior on lime-soil pile and CFG pile rigid-flexible pile composite subgrade," in Ground Improvement and GeosyntheticsAmerican Society of Civil Engineers, Shanghai, China, 2014.

[53] L. Yuan, Z. Keneng, L. Chuang, and H. Jie, "Test on enhancement coefficient of lateral resistance about CFG micro pile," Journal of Central South University of Technology, vol. 48, 2017.

[54] V. D. Tran, J.-J. Richard, and T. Hoang, "Soft soil improvement using rigid inclusions: toward an application for transport infrastructure construction in Vietnam," in New Prospects in Geotechnical Engineering Aspects of Civil Infrastructures, H. Khabbaz, H. Youn, and M. Bouassida, Eds., Springer International Publishing, Cham, Switzerland, 2019.

[55] L. Li, J. Huang, Q. Fu et al., "Centrifuge experimental study of mechanical properties of composite foundation with different replacement rates under additional load," Rock and Soil Mechanics, vol. 38, pp. 131-139, 2017.

[56] M. Zhao, Q. Chen, and L. Zhang, "Calculation of pile-soil stress ratio of rigid pile composite foundation with consideration of upward penetration of piles," Journal of Highway and Transportation Research and Development (English Edition), vol. 5, no. 1, pp. 1-6, 2011, https://doi.org/ 10.1061/JHTRCQ.0000033.

[57] M. Cao and A. Zhou, "Analytical solutions to interaction factors of two unequal length piles under horizontal loads," International Journal of Geomechanics, vol. 19, 2019 https:// doi.org/10.1061/(ASCE)GM.1943-5622.0001369, Article ID 06019003.

[58] W. Liu, X. Yang, S. Zhang, X. Kong, and W. Chen, “Analysis of deformation characteristics of long-short pile composite foundation in salt lake area, Iran," Advances in Civil Engineering, vol. 201915 pages, 2019, https://doi.org/10.1155/ 2019/5976540, Article ID 5976540.

[59] W. Liu, S. Qu, H. Zhang, and Z. Nie, “An integrated method for analyzing load transfer in geosynthetic-reinforced and pile-supported embankment," KSCE Journal of Civil Engineering, vol. 21, no. 3, pp. 687-702, 2017, https://doi.org/10. 1007/s12205-016-0605-3.

[60] B. B. Sheil, B. A. McCabe, E. M. Comodromos, and B. M. Lehane, "Pile groups under axial loading: an appraisal of simplified non-linear prediction models," Géotechnique, vol. 69 , no. 7, pp. 565-579, 2019, https://doi.org/10.1680/ jgeot.17.R.040.

[61] A. D. Wang, W. D. Wang, M. S. Huang, J. B. Wu, B. B. Sheil, and B. A. McCabe, "Discussion: interaction factor for large pile groups," Géotechnique Letters, vol. 6, no. 3, pp. 234-240, 2016, https://doi.org/10.1680/jgele.16.00082.

[62] S. C. Wong and H. G. Poulos, "Approximate pile-to-pile interaction factors between two dissimilar piles," Computers and Geotechnics, vol. 32, no. 8, pp. 613-618, 2005, https://doi. org/10.1016/j.compgeo.2005.11.001.

[63] X. Niu, Y. Yao, Y. Sun, Y. He, and H. Zhang, "3D numerical analysis of synergetic interaction between high-rise building basement and CFG piles foundation," Applied Sciences, vol. 8, no. 11, p. 2040, 2018, https://doi.org/10.3390/ app8112040.

[64] V. Fioravante, "Load transfer from a raft to a pile with an interposed layer," Géotechnique, vol. 61, no. 2, pp. 121-132, 2011, https://doi.org/10.1680/geot.7.00187.

[65] C. Junjun and W. Xinghua, "Post-construction settlement calculation and prediction for group piles foundation of high speed railway bridge," Advances in Natural Sciences: Nanoscience and Nanotechnology, vol. 8, pp. 1-7, 2016, https://doi.org/10.3968/7978.

[66] M. Zhang, J. J. Li, and C. H. K. Qin, “Analysis and discussion on post-construction settlement of soft soil foundation treatment test section of highway," IOP Conference Series: Earth and Environmental Science, vol. 81, 2017 https://doi. org/10.1088/1755-1315/81/1/012151, Article ID 012151. 
[67] G. Zheng, Y. Jiang, J. Han, and Y.-F. Liu, "Performance of cement-fly ash-gravel pile-supported high-speed railway embankments over soft marine clay," Marine Georesources \& Geotechnology, vol. 29, no. 2, pp. 145-161, 2011, https://doi. org/10.1080/1064119X.2010.532700.

[68] Z.-F. Wang, W.-C. Cheng, Y.-Q. Wang, and J.-Q. Du, "Simple method to pridict settlement of composite foundation under embankment," International Journal of Geomechanics, vol. 18, 2018 https://doi.org/10.1061/(ASCE)GM. 1943-5622.0001293, Article ID 04018158.

[69] M.-h. Zhao, L. Zhang, and M.-h. Yang, "Settlement calculation for long-short composite piled raft foundation," Journal of Central South University of Technology, vol. 13, no. 6, pp. 749-754, 2006, https://doi.org/10.1007/ s11771-006-0026-4.

[70] S.-H. Lee and C.-K. Chung, "An experimental study of the interaction of vertically loaded pile groups in sand," $\mathrm{Ca}$ nadian Geotechnical Journal, vol. 42, no. 5, pp. 1485-1493, 2005, https://doi.org/10.1139/t05-068.

[71] H. G. Poulos and E. H. Davis, Pile Foundation Analysis and Design, John Wiley \& Sons, New York, NY, USA, 1980.

[72] A. D. Wang, W. D. Wang, M. S. Huang, and J. B. Wu, "Interaction factor for large pile groups," Géotechnique Letters, vol. 6, no. 1, pp. 58-65, 2016, https://doi.org/10.1680/ jgele.15.00139.

[73] J. Castro and C. Sagaseta, "Consolidation and deformation around stone columns: numerical evaluation of analytical solutions," Computers and Geotechnics, vol. 38, no. 3, pp. 354-362, 2011, https://doi.org/10.1016/j.compgeo.2010. 12.006 .

[74] Q. Luo and Q. Lu, "Settlement calculation of rigid pile composite foundation considering pile-soil relative slip under embankment load," China Journal of Highway and Transport, vol. 31, pp. 20-30, 2018.

[75] M. Khabbazian, V. N. Kaliakin, and C. L. Meehan, "Column supported embankments with geosynthetic encased columns: Validity of the unit cell concept," Geotechnical and Geological Engineering, 2015.

[76] J. Lai, H. Liu, J. Qiu, and J. Chen, "Settlement analysis of saturated tailings dam treated by CFG pile composite foundation," Advances in Materials Science and Engineering, vol. 2016, Article ID 7383762, 10 pages, 2016.

[77] W. P. Cao and M. Zhao, "Performance of floating piles for supporting embankments in soft soils," Applied Mechanics and Materials, vol.105-107, pp. 1433-1437, 2011, https://doi. org/10.4028/www.scientific.net/AMM.105-107.1433.

[78] X. Gu, X. Tan, W. Huang, and G. Ren, "Failure mechanisms of embankment on inclined soft foundation reinforced by CFG Piles," Chinese Journal of Geotechnical Engineering, vol. 39, 2017.

[79] H. V. Pham, D. Dias, and A. Dudchenko, "3D modeling of geosynthetic-reinforced pile-supported embankment under cyclic loading," Geosynthetics International, vol. 27, no. 2, pp. 157-169, 2020.

[80] J. Zhang, J.-J. Zheng, B.-G. Chen, and J.-H. Yin, "Coupled mechanical and hydraulic modeling of a geosyntheticreinforced and pile-supported embankment," Computers and Geotechnics, vol. 52, pp. 28-37, 2013.

[81] Y. Jiang, J. Han, and G. Zheng, "Numerical analysis of a pileslab-supported railway embankment," Acta Geotechnica, vol. 9, no. 3, pp. 499-511, 2014, https://doi.org/10.1007/ s11440-013-0285-9.

[82] C. Xu, G. Ye, Z. Jiang, and Q. Zhou, "Research on mechanism of combined improvement of soft soils based on field monitoring," Chinese Journal of Geotechnical Engineering, vol. 28, pp. 918-921, 2006.

[83] H. Yu, Y. Wang, C. Zou, P. Wang, and C. Yan, "Study on subgrade settlement characteristics after widening project of highway built on weak foundation," Arabian Journal for Science and Engineering, vol. 42, no. 9, pp. 3723-3732, 2017, https://doi.org/10.1007/s13369-017-2469-3.

[84] M. A. Nunez, L. Briançon, and D. Dias, "Analyses of a pilesupported embankment over soft clay: full-scale experiment, analytical and numerical approaches," Engineering Geology, vol. 153, pp. 53-67, 2013, https://doi.org/10.1016/j.enggeo. 2012.11.006.

[85] J. J. Zheng, B. G. Chen, Y. E. Lu, S. W. Abusharar, and J. H. Yin, "The performance of an embankment on soft ground reinforced with geosynthetics and pile walls," Geosynthetics International, vol. 16, no. 3, pp. 173-182, 2009, https://doi.org/10.1680/gein.2009.16.3.173.

[86] M. Raithel, A. Kirchner, and H. G. Kempfert, "German recommendations for reinforced embankments on pilesimilar elements," in Geosynthetics in Civil and Environmental Engineering, G. Li, Y. Chen, and X. Tang, Eds., Springer, Berlin, Heidelberg, Germany, 2008.

[87] J. Zhang, J.-j. Zheng, and Q. Ma, "Mechanical analysis of fixed geosynthetic technique of GRPS embankment," Journal of Central South University, vol. 20, no. 5, pp. 1368-1375, 2013, https://doi.org/10.1007/s11771-013-1624-6.

[88] D. F. Fagundes, M. S. S. Almeida, L. Thorel, and M. Blanc, "Load transfer mechanism and deformation of reinforced piled embankments," Geotextiles and Geomembranes, vol. 45, no. 2, pp. 1-10, 2017, https://doi.org/10.1016/j. geotexmem.2016.11.002.

[89] J. Han, A. Bhandari, and F. Wang, "DEM analysis of stresses and deformations of geogrid-reinforced embankments over piles," International Journal of Geomechanics, vol. 12, no. 4, pp. 340-350, 2012, https://doi.org/10.1061/(ASCE)GM.19435622.0000050

[90] R. Roy and A. Bhasi, "Investigation of arching effect in geosynthetic-reinforced piled embankments," Iranian Journal of Science and Technology, Transactions of Civil Engineering, vol. 43, no. S1, pp. 249-262, 2019, https://doi. org/10.1007/s40996-018-0162-8.

[91] R. Rui, J. Han, S. J. M. van Eekelen, and Y. Wan, "Experimental investigation of soil-arching development in unreinforced and geosynthetic-reinforced pile-supported embankments," Journal of Geotechnical \& Geoenvironmental Engineering, vol. 145, 2019 https://doi.org/10.1061/(ASCE) GT.1943-5606.0002000, Article ID 04018103.

[92] Q. Anh Tran, P. Villard, and D. Dias, "Discrete and Continuum Numerical Modeling of Soil Arching between Piles," International Journal of Geomechanics, vol. 19, Article ID 04018195, 2019.

[93] K. Ghaffari Irdmoosa and H. Shahir, "Analytical solution for active earth pressure of $c-\varphi$ soil considering arching effect," Geomechanics and Geoengineering, vol. 14, no. 2, pp. 71-84, 2018, https://doi.org/10.1080/17486025.2018.1533649.

[94] Y. M. A. Hashash and A. J. Whittle, "Mechanisms of load transfer and arching for braced excavations in clay," Journal of Geotechnical and Geoenvironmental Engineering, vol. 128, no. 3, pp. 187-197, 2002, https://doi.org/10.1061/.

[95] G.-F. He, Z.-G. Li, Y. Yuan et al., "Optimization analysis of the factors affecting the soil arching effect between landslide stabilizing piles," Natural Resource Modeling, vol. 31, 2018 https://doi.org/10.1111/nrm.12148, Article ID e12148. 
[96] C. J. Lee, B. R. Wu, H. T. Chen, and K. H. Chiang, "Tunnel stability and arching effects during tunneling in soft clayey soil," Tunnelling and Underground Space Technology, vol. 21, no. 2, pp. 119-132, 2006, https://doi.org/10.1016/j.tust.2005. 06.003.

[97] A. Roy and N. R. Patra, "Effect of arching on passive earth pressure for rigid retaining walls considering translation mode," in Structures Congress 2009American Society of Civil Engineers, Austin, TX, USA, 2009.

[98] K. Terzaghi, R. B. Peck, and G. Mesri, Soil Mechanics in Engineering Practice, Wiley, New York, NY, USA, 3rd edition, 1996.

[99] Y.-t. Zhou, Q.-s. Chen, F.-q. Chen, X.-h. Xue, and S. Basack, "Active earth pressure on translating rigid retaining structures considering soil arching effect," European Journal of Environmental and Civil Engineering, vol. 22, no. 8, pp. 910-926, 2018, https://doi.org/10.1080/19648189.2016. 1229225.

[100] L. Briançon and B. Simon, "Performance of pile-supported embankment over soft soil: full-scale experiment," Journal of Geotechnical and Geoenvironmental Engineering, vol. 138, no. 4, pp. 551-561, 2012, https://doi.org/10.1061/(ASCE)GT. 1943-5606.0000561.

[101] J. Han and M. A. Gabr, "Numerical analysis of geosyntheticreinforced and pile-supported earth platforms over soft soil," Journal of Geotechnical and Geoenvironmental Engineering, vol. 128, no. 1, pp. 44-53, 2002.

[102] K. Fei and H. Liu, "Field test study and numerical analysis of a geogridreinforced and pile-supported embankment," Rock and Soil Mechanics, vol. 30, pp. 1005-1012, 2009.

[103] G. Liu, L. Kong, and X. Li, "Analysis of treatment scheme for soft foundation on in expressway widening project and its verification," Chinese Journal of Rock Mechanics and Engineering, vol. 27, pp. 309-315, 2008.

[104] D. B. Zhang, Y. Zhang, T. Cheng, and J. Y. Yuan, "Soft foundation strengthening effect and structural optimization of a new cement fly-ash and gravel pile-slab structure," IJE Tranactions Basics, vol. 30, pp. 955-963, 2017.

[105] M. F. Bransby and S. M. Springman, "Centrifuge modelling of pile groups adjacent to surcharge loads," Soils and Foundations, vol. 37, no. 2, pp. 39-49, 1997, https://doi.org/ 10.3208/sandf.37.2_39.

[106] E. A. Ellis and S. M. Springman, "Modelling of soil-structure interaction for a piled bridge abutment in plane strain FEM analyses," Computers and Geotechnics, vol. 28, no. 2, pp. 79-98, 2001, https://doi.org/10.1016/S0266-352X(00) 00025-2.

[107] D. Li and D. Davis, "Transition of railroad bridge approaches," Journal of Geotechnical and Geoenvironmental Engineering, vol. 131, no. 11, pp. 1392-1398, 2005.

[108] B. M. Phares, A. S. Faris, L. Greimann, and D. Bierwagen, "Integral bridge abutment to approach slab connection," Journal of Bridge Engineering, vol. 18, no. 2, pp. 179-181, 2013, https://doi.org/10.1061/(ASCE)BE.1943-5592.0000333.

[109] D. P. Stewart, R. J. Jewell, and M. F. Randolph, "Design of piled bridge abutments on soft clay for loading from lateral soil movements," Géotechnique, vol. 44, no. 2, pp. 277-296, 1994, https://doi.org/10.1680/geot.1994.44.2.277.

[110] D. Xiao, G. L. Jiang, D. Liao, Y. F. Hu, and X. F. Liu, "Influence of cement-fly ash-gravel pile-supported approach embankment on abutment piles in soft ground," Journal of Rock Mechanics and Geotechnical Engineering, vol. 10, no. 5, pp. 977-985, 2018, https://doi.org/10.1016/j.jrmge.2018.06. 001.
[111] D. Xiao, G. Jiang, Z. Lin et al., "Analysis on working properties of abutment piles considering foundation reinforcement of approach embankment," Journal of Central South University of Technology, vol. 48, pp. 820-829, 2017.

[112] W. Li and X. Bian, "Dynamic performance of pile-supported bridge-embankment transition zones under high-speed train moving loads," Procedia Engineering, vol. 143, pp. 10591067, 2016, https://doi.org/10.1016/j.proeng.2016.06.101.

[113] X. Han, Y. Li, J. Ji, J. Ying, W. Li, and B. Dai, "Numerical simulation on the seismic absorption effect of the cushion in rigid-pile composite foundation," Earthquake Engineering and Engineering Vibration, vol. 15, no. 2, pp. 369-378, 2016, https://doi.org/10.1007/s11803-016-0329-x.

[114] X. Zhu, K. Fei, and S. Wang, "Horizontal loading tests on disconnected piled rafts and a simplified method to evaluate the horizontal bearing capacity," Advances in Civil Engineering, vol. 2018, Article ID 3956509, 12 pages, 2018.

[115] J. Ding, X. Quan, E. Du, and T. Zhao, "Dynamic characteristics on composite foundation with CFG pile," Journal of Civil, Architectural \& Environmental Engineering, vol. 1, pp. 104-109, 2014.

[116] J. Ding, W. Wang, T. Zhao, J. Feng, and P. Zhang, "The dynamic characteristic experimental method on the composite foundation with rigid-flexible compound piles," Open Journal of Civil Engineering, vol. 3, no. 2, pp. 94-98, 2013.

[117] Y. Feng, Y. Wang, and C. Zhang, "The analysis of composite foundation with CFG and gravel piles to resist soil liquefaction," in Geotechnical Enginnering for Disaster Mitigation and Rehabilitation, H. Liu, A. Deng, and J. Chu, Eds., Springer, Berlin, Germany, 2008.

[118] C. Yang, K. Ni, and S. Wang, "Analysis of the stress characteristics of CFG pile composite foundation under irregularity condition," Stavební Obzor-Civil Engineering Journal, vol. 26, no. 2, pp. 154-166, 2017, https://doi.org/10.14311/ CEJ.2017.02.0014

[119] L. Li, J. Huang, and B. Han, "Centrifugal investigation of excavation adjacent to existing composite foundation," Journal of Performance of Constructed Facilities, vol. 32, 2018 https://doi.org/10.1061/(ASCE)CF.1943-5509.0001188, Article ID 04018044.

[120] L. Ma, "Research on design of CFG pile composite foundation for high-rise buildings," Value Engineering, vol. 39, pp. 145-146, 2020.

[121] G.-h. Wang and Y.-y. Yang, "Effect of cantilever soldier pile foundation excavation closing to an existing composite foundation," Journal of Central South University, vol. 20, no. 5, pp. 1384-1396, 2013, https://doi.org/10.1007/s11771013-1626-4.

[122] Y. Yuan, A. Liu, Y. Jiao, and C. Liu, "Field detection and simulation analysis of CFG pile composite foundation," Journal of Civil Engineering, vol. 7, pp. 906-918, 2018.

[123] Z. Q. Xie, C. Jun, H. B. Xiao, and Z. Y. Li, "Application of CFG piles in treatment of a large oil tank foundation," Advanced Materials Research, vol. 446-449, pp. 2518-2522, 2012, https://doi.org/10.4028/www.scientific.net/AMR.446449.2518.

[124] C. Bohn, Serviceability and Safety in the Design of Rigid Inclusions and Combined Pile-Raft Foundations, Ph.D. Dissertation, Department of Civil Engineering, Université Paris-Est, Champs-sur-Marne, France, 2015.

[125] H. Rasouli and B. Fatahi, "A novel cushioned piled raft foundation to protect buildings subjected to normal fault rupture," Computers and Geotechnics, vol. 106, pp. 228-248, 2019, https://doi.org/10.1016/j.compgeo.2018.11.002. 
[126] M. El Sawwaf, "Experimental study of eccentrically loaded raft with connected and unconnected short piles," Journal of Geotechnical and Geoenvironmental Engineering, vol. 136, no. 10, pp. 1394-1402, 2010, https://doi.org/10.1061/(ASCE) GT.1943-5606.0000341.

[127] F. Tradigo, F. Pisanò, C. di Prisco, and A. Mussi, "Non-linear soil-structure interaction in disconnected piled raft foundations," Computers and Geotechnics, vol. 63, pp. 121-134, 2015, https://doi.org/10.1016/j.compgeo.2014.08.014.

[128] I. H. Wong, M. F. Chang, and X. D. Cao, "Raft foundations with disconnected settlement-reducing piles," in Design Applications of Raft Foundations Thomas Telford Publishing, London, UK, 2000.

[129] M. H. Baziar, F. Rafiee, C. J. Lee, and A. Saeedi Azizkandi, "Effect of superstructure on the dynamic response of nonconnected piled raft foundation using centrifuge modeling," International Journal of Geomechanics, vol. 18, 2018 https:// doi.org/10.1061/(ASCE)GM.1943-5622.0001263, Article ID 04018126.

[130] X. D. Cao, I. H. Wong, and M.-F. Chang, "Behavior of model rafts resting on pile-reinforced sand," Journal of Geotechnical and Geoenvironmental Engineering, vol. 130, no. 2, pp. 129-138, 2004, https://doi.org/10.1061/.

[131] Y. Min, "Study on reducing_settlement pile foundation based on controlling settlement principle," Chinese Journal of Geotechnical Engineering, vol. 22, pp. 481-486, 2000.

[132] H. G. Poulos, "Piled raft foundations: design and applications," Géotechnique, vol. 51, no. 2, pp. 95-113, 2001, https:// doi.org/10.1680/geot.2001.51.2.95.

[133] M. Ghanbar Dezfouli, M. Dehghani, A. Asakereh, and B. Kalantari, "Behavior of geogrid reinforced and unreinforced non-connected pile raft foundation," International Journal of Civil Engineering, vol. 17, no. 6, pp. 709-722, 2019, https://doi.org/10.1007/s40999-018-0362-4.

[134] H. Rasouli, A. Saeedi Azizkandi, M. H. Baziar et al., "Centrifuge modeling of non-connected piled raft system," International Journal of Civil Engineering, vol. 13, 2015.

[135] A. Saeedi Azizkandi, H. Rasouli, and M. H. Baziar, "Load sharing and carrying mechanism of piles in non-connected pile rafts using a numerical approach," International Journal of Civil Engineering, vol. 17, no. 6, pp. 793-808, 2019, https:// doi.org/10.1007/s40999-018-0356-2.

[136] M. Yang and S. Liu, "Field tests and finite element modeling of a prestressed concrete pipe pile-composite foundation," KSCE Journal of Civil Engineering, vol. 19, no. 7, pp. 20672074, 2015, https://doi.org/10.1007/s12205-015-0549-z.

[137] S. Nakai, H. Kato, R. Ishida et al., "Load bearing mechanism of piled raft foundation during earthquake," in Proceedings of the Third UJNR Workshop on Soil-Structure Interaction, Menlo Park, CA, USA, 2004.

[138] X. Zhu, W. Kong, W. Gong et al., "Test on the horizontal characteristics of disconnected piles raft foundation," China Journal of Highway and Transport, vol. 32, pp. 97-115, 2019.

[139] A. S. Azizkandi, M. H. Baziar, and A. F. Yeznabad, "3D dynamic finite element analyses and $1 \mathrm{~g}$ shaking table tests on seismic performance of connected and nonconnected piled raft foundations," KSCE Journal of Civil Engineering, vol. 22, no. 5, pp. 1750-1762, 2018, https://doi.org/10.1007/ s12205-017-0379-2.

[140] R. Xu and B. Fatahi, "Geosynthetic-reinforced cushioned piles with controlled rocking for seismic safeguarding," Geosynthetics International, vol. 25, no. 6, pp. 561-581, 2018, https://doi.org/10.1680/jgein.18.00018.
[141] D. Basu, A. Misra, and A. J. Puppala, "Sustainability and geotechnical engineering: perspectives and review," Canadian Geotechnical Journal, vol. 52, no. 1, pp. 96-113, 2015, https://doi.org/10.1139/cgj-2013-0120.

[142] M. Samanta, "Investigation on geomechanical behaviour and microstructure of cement-stabilized fly ash," International Journal of Geotechnical Engineering, vol. 12, no. 5, pp. 449-461, 2018, https://doi.org/10.1080/19386362.2017. 1295623.

[143] S. Liang, J. Chen, M. Guo, D. Feng, L. Liu, and T. Qi, "Utilization of pretreated municipal solid waste incineration fly ash for cement-stabilized soil," Waste Management, vol. 105, pp. 425-432, 2020, https://doi.org/10.1016/j. wasman.2020.02.017.

[144] K.-Y. Show, J.-H. Tay, and A. T. C. Goh, "Reuse of incinerator fly ash in soft soil stabilization," Journal of Materials in Civil Engineering, vol. 15, no. 4, pp. 335-343, 2003.

[145] C. Spaulding, F. Masse, and J. LaBrozzi, "Ground improvement technologies for a sustainable World," in GeoCongress 2008American Society of Civil Engineers, New Orleans, LA, USA, 2008.

[146] B. Zhang, S. Cui, Z. Liu, and F. Feng, "Field tests of cement fly-ash steel-slag pile composite foundation," Journal of Testing and Evaluation, vol. 45, no. 3, https://doi.org/10. 1520/JTE20140422, Article ID 20140422, 2017.

[147] D. P. Jiang and B. L. Wang, "An analysis on failure pattern of CFG pile-net composite foundation of high-speed railway," Advanced Materials Research, vol. 594-597, pp. 1357-1362, 2012, https://doi.org/10.4028/www.scientific.net/AMR.594597.1357.

[148] Q. Xu, Y. Song, and X. Han, “Application of CFG piles to soft soil treatment of municipal engineering," in Mechanical Engineering and Control SystemsWorld Scientific, Wuhan, China, 2016.

[149] L. Deng, "CFG pile based soft foundation treatment," Applied Mechanics and Materials, vol. 484-485, pp. 790-795, 2014, https://doi.org/10.4028/www.scientific.net/AMM.484485.790.

[150] W. N. Abd El Samee, "Effect of shape and depth of shallow foundations on failure mechanism and Wedge angle of sandy soil," in Advanced Research on Shallow Foundations, H. Shehata and B. Das, Eds., Springer International Publishing, Cham. Switzerland, 2019.

[151] Y. Chi, W. Shen, and E. Song, "Discussion on pile soil relationship between failure model of cushion and stress ratio," Industrial Construction, vol. 31, pp. 9-11, 2001.

[152] IREX, Recommendations for the Design, Construction and Control of Rigid Inclusion Ground Improvements, Presses des Ponts, Paris, France, 2012.

[153] F. Wang, F. Zhu, S. Wang, and T. Dong, "Cushion design of composite foundation," Journal of Northeast Normal University (Natural Science Edition), vol. 25, pp. 287-290, 2004.

[154] R. Rui, Y. Sun, Y. Zhu et al., "Mesoscopic working mechanism of cushion of composite foundation under rigid slab," Rock and Soil Mechanics, vol. 40, pp. 445-454, 2019.

[155] X. Zhu and W. Gong, "Study on soil arching in the cushion of composite foundation," in Soil Behavior and GeomechanicsAmerican Society of Civil Engineers, Shanghai, China, 2014.

[156] M. Al-Naddaf, J. Han, C. Xu et al., "Experimental investigation of soil arching mobilization and degradation under localized surface loading," Journal of Geotechnical \& Geoenvironmental Engineering, vol. 145, 2019 https://doi.org/10. 1061/(ASCE)GT.1943-5606.0002190, Article ID 04019114. 
[157] T. A. Pham, "Analysis of geosynthetic-reinforced pile-supported embankment with soil-structure interaction models," Computers and Geotechnics, vol. 121, 2020 https://doi.org/10. 1016/j.compgeo.2020.103438, Article ID 103438.

[158] S. J. M. van Eekelen and J. Han, "Geosynthetic-reinforced pile-supported embankments: state of the art," Geosynthetics International, vol. 27, no. 2, pp. 112-141, 2020, https://doi. org/10.1680/jgein.20.00005.

[159] S. J. M. van Eekelen, A. Bezuijen, and A. F. van Tol, "An analytical model for arching in piled embankments," Geotextiles and Geomembranes, vol. 39, pp. 78-102, 2013, https:// doi.org/10.1016/j.geotexmem.2013.07.005.

[160] P. Ariyarathne and D. S. Liyanapathirana, "Review of existing design methods for geosynthetic-reinforced pilesupported embankments," Soils and Foundations, vol. 55, no. 1, pp. 17-34, 2015, https://doi.org/10.1016/j.sandf.2014. 12.002 .

[161] P. Shen, C. Xu, and J. Han, "Centrifuge tests to investigate global performance of geosynthetic-reinforced pile-supported embankments with side slopes," Geotextiles and Geomembranes, vol. 48, no. 1, pp. 120-127, 2020, https://doi. org/10.1016/j.geotexmem.2019.103527.

[162] S. J. M. van Eekelen, A. Bezuijen, H. J. Lodder, and A. F. van Tol, "Model experiments on piled embankments: part I," Geotextiles and Geomembranes, vol. 32, pp. 69-81, 2012, https://doi.org/10.1016/j.geotexmem.2011.11.002.

[163] A. Bhasi and K. Rajagopal, "Numerical study of basal reinforced embankments supported on floating/end bearing piles considering pile-soil interaction," Geotextiles and Geomembranes, vol. 43, no. 6, pp. 524-536, 2015, https://doi. org/10.1016/j.geotexmem.2015.05.003.

[164] P. Shen, C. Xu, and J. Han, "Geosynthetic-reinforced pilesupported embankment: settlement in different pile conditions," Geosynthetics International, vol. 27, no. 3, pp. 315-331, 2020.

[165] I. V. L. Chango, M. Yan, X. Ling, T. Liang, and O. C. Assogba, "Dynamic response analysis of geogrid reinforced embankment supported by CFG pile structure during a high-speed train operation," Latin American Journal of Solids and Structures, vol. 16, no. 7, https://doi.org/ 10.1590/1679-78255710, Article ID e214, 2019.

[166] C. Zhang, G. Jiang, X. Liu, and O. Buzzi, “Arching in geogrid-reinforced pile-supported embankments over silty clay of medium compressibility: field data and analytical solution," Computers and Geotechnics, vol. 77, pp. 11-25, 2016, https://doi.org/10.1016/j.compgeo.2016.03.007.

[167] G.-B. Ye, M. Wang, Z. Zhang, J. Han, and C. Xu, "Geosynthetic-reinforced pile-supported embankments with caps in a triangular pattern over soft clay," Geotextiles and Geomembranes, vol. 48, no. 1, pp. 52-61, 2020, https://doi. org/10.1016/j.geotexmem.2019.103504.

[168] M. Wijerathna and D. S. Liyanapathirana, "Load transfer mechanism in geosynthetic reinforced column-supported embankments," Geosynthetics International, vol. 27, no. 3, pp. 236-248, 2020.

[169] C. Wang, S. Zhou, B. Wang, and P. Guo, "Time effect of pilesoil-geogrid-cushion interaction of rigid pile composite foundations under high-speed railway embankments," Geomechanics and Engineering, vol. 16, pp. 589-597, 2018.

[170] A. Ata, E. Badrawi, and M. Nabil, "Numerical analysis of unconnected piled raft with cushion," Ain Shams Engineering Journal, vol. 6, no. 2, pp. 421-428, 2015, https://doi. org/10.1016/j.asej.2014.11.002.
[171] H. Dan, L. Li, L. Zhao, and F. Wan, "Calculation and influence factors analysis on pile-soil stress ratio of CFG pile composite foundation," China Railway Science, vol. 29, pp. 7-12, 2008.

[172] J. Fu and E. Song, "Analysis of rigid pile composite foundation's working performance," Rock and Soil Mechanics, vol. 21, pp. 335-339, 2000.

[173] C. Guo, S. W. Xiao, and Z. L. Chen, "Study of low strength pile composite foundation deformation \& stability calculation method," Applied Mechanics and Materials, vol. 170-173, pp. 545-556, 2012, https://doi.org/10.4028/ www.scientific.net/AMM.170-173.545.

[174] B. Broms, "Negative skin friction," in Proceedings of 6th Asian Regional Asian Conference on Soil Mechanics and Foundation Engineering, pp. 41-75, Singapore, 1979.

[175] C. J. Lee, M. D. Bolton, and A. Al-Tabbaa, "Numerical modelling of group effects on the distribution of dragloads in pile foundations," Géotechnique, vol. 52, no. 5, pp. 325-335, 2002.

[176] D. Loukidis and R. Salgado, "Analysis of the shaft resistance of non-displacement piles in sand," Géotechnique, vol. 58, no. 4, pp. 283-296, 2008, https://doi.org/10.1680/geot.2008. 58.4.283.

[177] J. Li, J. Cong, N. Li, and J. Cao, "Study on the design method of CFG pile composite foundation for storage tanks based on the settlement controlling," Journal of Hohai University (Natural Sciences), vol. 46, pp. 321-328, 2018.

[178] S. Yan, R. Lang, L. Sun et al., "Calculation of pile-soil stress ratio in composite foundation with rigid pile-net based on plate theory," Chinese Journal of Rock Mechanics and Engineering, vol. 36, pp. 2051-2060, 2017.

[179] T. Ma, Y. Zhu, X. Yang, and Y. Ling, "Bearing characteristics of composite pile group foundations with long and short piles under lateral loading in loess areas," Mathematical Problems in Engineering, vol. 2018, Article ID 8145356, 17 pages, 2018.

[180] R. B. Peck, "Deep excavations and tunneling in soft ground," in Proceedings of the 7th International Conference on Soil Mechanics and Foundation Engineering, pp. 225-290, Mexico, MX, USA, 1969.

[181] H. Chen, J. Li, C. Yang, and C. Feng, "A theoretical study on ground surface settlement induced by a braced deep excavation," European Journal of Environmental and Civil Engineering, pp. 1-20, 2020.

[182] G. W. Clough and T. D. O’Rourke, "Construction induced movements of insitu walls," in Design and Performance of Earth Retaining StructuresASCE Geotechnical Special Publication, New York, NY, USA, 1990.

[183] X. Zhang, J. Yang, Y. Zhang, and Y. Gao, "Cause investigation of damages in existing building adjacent to foundation pit in construction," Engineering Failure Analysis, vol. 83, pp. 117-124, 2018, https://doi.org/10.1016/j. engfailanal.2017.09.016.

[184] W. G. Zhang, A. T. C. Goh, K. H. Goh, O. Y. S. Chew, D. Zhou, and R. Zhang, "Performance of braced excavation in residual soil with groundwater drawdown," Underground Space, vol. 3, no. 2, pp. 150-165, 2018, https://doi.org/10. 1016/j.undsp.2018.03.002.

[185] H. G. Poulos, "Ground movements - a hidden source of loading on deep foundations," DFI Journal-The Journal of the Deep Foundations Institute, vol. 1, no. 1, pp. 37-53, 2007, https://doi.org/10.1179/dfi.2007.004.

[186] A. Yao, J. Lu, Y. Guo et al., "Reinforcement effects of isolation piles on the adjacent existing tunnel in building 
construction," Advances in Materials Science and Engineering, vol. 2019, Article ID 9741306, 21 pages, 2019.

[187] O. Demeijer, J.-J. Chen, M.-G. Li et al., "Influence of passively loaded piles on excavation-induced diaphragm wall displacements and ground settlements," International Journal of Geomechanics, vol. 18, 2018 https://doi.org/10. 1061/(ASCE)GM.1943-5622.0001126, Article ID 04018052.

[188] G. Pittaro, "Tensile strength behaviour of ground improvement and its importance on deep excavations using deep soil mixing," in Proceedings of the XVII European Conference on Soil Mechanics and Geotechnical Engineering, pp. 415-422, Reykjavik, Iceland, September 2019.

[189] Y. S. Fang and I. Ishibashi, "Static earth pressures with various wall movements," Journal of Geotechnical Engineering, vol. 112, no. 3, pp. 317-333, 1986.

[190] R. J. Finno, S. Kim, J. Lewis, and N. Van Winkle, "Observed performance of a sheetpile-supported excavation in chicago clays," Journal of Geotechnical \& Geoenvironmental Engineering, vol. 145, 2019 https://doi.org/10.1061/(ASCE)GT. 1943-5606.0002010, Article ID 05018005.

[191] M. Georgiadis and C. Anagnostopoulos, "Lateral pressure on sheet pile walls due to strip load," Journal of Geotechnical and Geoenvironmental Engineering, vol. 124, no. 1, pp. 95-98, 1998.

[192] P.-G. Hsieh and C.-Y. Ou, "Shape of ground surface settlement profiles caused by excavation," Canadian Geotechnical Journal, vol. 35, no. 6, pp. 1004-1017, 1998, https://doi. org/10.1139/t98-056.

[193] M. H. Khosravi, T. Pipatpongsa, and J. Takemura, "Theoretical analysis of earth pressure against rigid retaining walls under translation mode," Soils and Foundations, vol. 56, no. 4, pp. 664-675, 2016, https://doi.org/10.1016/j.sandf. 2016.07.007.

[194] Y. Tang, J. Pei Li, and Y. Ma, "Lateral earth pressure considering the displacement of a rigid retaining wall," International Journal of Geomechanics, vol. 18, 2018 https://doi. org/10.1061/(ASCE)GM.1943-5622.0001284, Article ID 06018031.

[195] Q. Fu and L. Li, "Vertical load transfer behavior of composite foundation and its responses to adjacent excavation: centrifuge model test," Geotechnical Testing Journal, vol. 44, no. 1, https://doi.org/10.1520/GTJ20180237, Article ID 20180237, 2021.

[196] L. Li and Q. Fu, "Lateral mechanical behavior of composite ground due to adjacent excavation: centrifuge model test," China Civil Engineering Journal, vol. 50, pp. 85-94, 2017.

[197] G. F. Ren and J. S. Qiao, "Research on the mechanical behavior effect of around composite foundation under soil lateral displacement," Applied Mechanics and Materials, vol. 353-356, pp. 696-701, 2013, https://doi.org/10.4028/ www.scientific.net/AMM.353-356.696.

[198] D. S. Liyanapathirana and R. Nishanthan, "Influence of deep excavation induced ground movements on adjacent piles," Tunnelling and Underground Space Technology, vol. 52, pp. 168-181, 2016, https://doi.org/10.1016/j.tust.2015.11.019.

[199] R. Zhang, W. Zhang, and A. T. C. Goh, "Numerical investigation of pile responses caused by adjacent braced excavation in soft clays," International Journal of Geotechnical Engineering, pp. 1-15, 2018, https://doi.org/10.1080/ 19386362.2018.1515810.

[200] R. Fuentes, A. Pillai, and P. Ferreira, "Lessons learnt from a deep excavation for future application of the observational method," Journal of Rock Mechanics and Geotechnical
Engineering, vol. 10, no. 3, pp. 468-485, 2018, https://doi.org/ 10.1016/j.jrmge.2017.12.004

[201] R. B. Peck, "Advantages and limitations of the observational method in applied soil mechanics," Géotechnique, vol. 19, no. 2, pp. 171-187, 1969, https://doi.org/10.1680/geot.1969. 19.2.171.

[202] A. J. Powderham, "The observational method-learning from projects," Proceedings of the Institution of Civil EngineersGeotechnical Engineering, vol. 155, no. 1, pp. 59-69, 2002, https://doi.org/10.1680/geng.2002.155.1.59.

[203] J. Spross and F. Johansson, "When is the observational method in geotechnical engineering favourable?" Structural Safety, vol. 66, pp. 17-26, 2017, https://doi.org/10.1016/j. strusafe.2017.01.006.

[204] M. Calvello, "From the observational method to "observational modelling" of geotechnical engineering boundary value problems," in Geotechnical Safety and ReliabilityAmerican Society of Civil Engineers, Denver, Colorado, 2017.

[205] F. Wang, Engineering Characteristics of Solid Pile Composite Foundation, Ph.D. Dissertation, Northeastern University, Boston, MA, USA, 2003.

[206] X.-j. Zhu, "Analysis of the load sharing behaviour and cushion failure mode for a disconnected piled raft," $A d$ vances in Materials Science and Engineering, vol. 201713 pages, 2017, https://doi.org/10.1155/2017/ 3856864, Article ID 3856864.

[207] J. Zheng, J. Chen, H. Luo, and Y. Lu, "Analyzing failure modes and appropriate thickness of the cushion on rigid pile composite ground," Journal of Huazhong University of Science and Technology (Nature Science), vol. 36, pp. 120-124, 2008.

[208] Y. Dong, J. Zheng, and J. Zhang, "Analysis of flow and failure mechanism of cushion in rigid pile composite foundation," Advanced Materials Research, vol. 168-170, pp. 1491-1495, 2011.

[209] S. Varaksin, B. Hamidi, N. Huybrechts, and N. Denies, Ground Improvement vs. Pile Foundations?, WTCB-CSTC, Leuven, Belgium, 2016.

[210] M. Kitazume, K. Orano, and S. Miyajima, "Centrifuge model tests on failure envelope of column type deep mixing method improved ground," Soils and Foundations, vol. 40, no. 4, pp. 43-55, 2000, https://doi.org/10.3208/sandf.40.4_43.

[211] J. Yao, Research of Flow plastic soft soil composite foundation failure mechanism and processing method, Ph.D. Dissertation, China Academy of Railway Science, Beijing, China, 2015.

[212] N. N. S. Yapage, D. S. Liyanapathirana, and C. J. Leo, "Failure modes for geosynthetic reinforced column supported (GRCS) embankments," in Proceedings of the 18th International Conference on Soil Mechanics and Geotechnical Engineering, pp. 849-852, Paris, France, 2013.

[213] G. Zheng, S. Li, and Y. Daio, "Centrifugal model tests on failure mechanisms of embankments on soft ground reinforced by rigid piles," Chinese Journal of Geotechnical Engineering, vol. 34, pp. 1977-1989, 2012.

[214] D. Miao and J. Liu, "Study of failure mode of CFG pile in conmposite foundation under embankment by centrifugal model test," Guangdong Highway Communications, vol. 10-13, 2016.

[215] X. Wu, X. Dai, K. Zhang et al., "Study on centrifugal model test of rigid pile foundation," Journal of Civil Engineering and Management, vol. 35, pp. 13-19, 2018. 
[216] BS 8006-1, Code of Practice for Strengthened/reinforced Soils and Other Fills, British Standards Institution, ISBN, London, UK, 2010.

[217] J.-F. Chen, L.-Y. Li, J.-F. Xue, and S.-Z. Feng, "Failure mechanism of geosynthetic-encased stone columns in soft soils under embankment," Geotextiles and Geomembranes, vol. 43, no. 5, pp. 424-431, 2015, https://doi.org/10.1016/j. geotexmem.2015.04.016.

[218] M. Kitazume, "A parametric study on evaluation of stability of column type DM improved ground," in Advances in Environmental Geotechnics, Y. Chen, L. Zhan, and X. Tang, Eds., Springer, Berlin, Heidelberg, Germany, 2010.

[219] B. B. Broms, "Lime and lime/cement columns," in Ground Improvement, M. P. Moseley and K. Kirsch, Eds., Spon Press, London, UK, 2004.

[220] M. Kitazume, Stability of Group Column Type DMImproved Ground under Embankment Loading, Port and Airport Research Institute, Yokosuka, Kanagawa, Japan, 2008.

[221] W. Hang, "Analysis of causes of CFG pile necking in saturated soft soil layer and its control measures," World Construction, vol. 5, 2016 https://doi.org/10.18686/wc.v5i2.74.

[222] F. Teng, "Quality control of CFG pile composite foundation in construction," Value Engineering, vol. 38, pp. 14-15, 2019.

[223] G. Ren and Z. Shi, "Analysis on disqualified bearing capacity of individual pile in CFG pile composite foundation," Architectural Technology, vol. 47, pp. 1107-1109, 2016.

[224] G. x. Zhu and Y. Han, "Study on quality detection and reinforcement effect of CFG pile," IOP Conference Series Materials Science and Engineering, vol. 394, 2018 https://doi. org/10.1088/1757-899X/394/3/032079, Article ID 032079.

[225] L. Zhang, W. Qing, S. Sun, and H. Li, "Researching the application of CFG pile treatment in soft foundation of expressway," in Proceedings of the First International Conference on Information Sciences, Machinery, Materials and Energy, Atlantis Press, Chongqing, China, 2015.

[226] S. You, X. Cheng, H. Guo, and Z. Yao, "Experimental study on structural response of CFG energy piles," Applied Thermal Engineering, vol. 96, pp. 640-651, 2016, https://doi. org/10.1016/j.applthermaleng.2015.11.127.

[227] Q. Li and L. An, "Analysis of temperature field of embankment-CFG piles composite soft soil foundation system in cold regions," IOP Conference Series: Earth and Environmental Science, vol. 189, 2018 https://doi.org/10.1088/ 1755-1315/189/2/022037, Article ID 022037.

[228] S. Aoyama, W. Mao, S. Goto, and I. Towhata, "Application of advanced procedures to model tests on the subsoil behavior under vertical loading of group pile in sand," Indian Geotechnical Journal, vol. 46, no. 1, pp. 64-76, 2016, https://doi. org/10.1007/s40098-015-0152-8.

[229] M. Li and J. Zhao, "Progress of research advance on the model tests on the interaction between new constructions and adjacent existing buildings," in Proceedings of the GeoShanghai 2018 International Conference: Tunnelling and Underground Construction, D. Zhang and X. Huang, Eds., Springer Singapore, Singapore, 2018.

[230] M. T. Suleiman, L. Ni, J. D. Helm, and A. Raich, "Soil-pile interaction for a small diameter pile embedded in granular soil subjected to passive loading," Journal of Geotechnical \& Geoenvironmental Engineering, vol. 140, 2014 https://doi.org/10. 1061/(ASCE)GT.1943-5606.0001081, Article ID 04014002.

[231] R. Rui, Y. X. Zhai, J. Han, S. J. M. van Eekelen, and C. Chen, "Deformations in trapdoor tests and piled embankments," Geosynthetics International, vol. 27, no. 2, pp. 219-235, 2020, https://doi.org/10.1680/jgein.19.00014. 